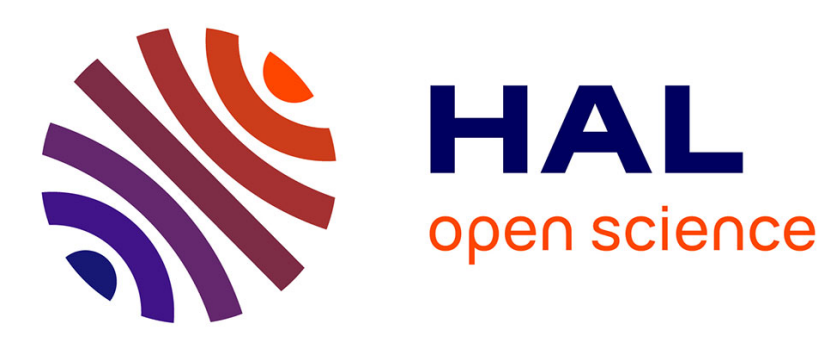

\title{
Including Sustainability Criteria into Inventory Models
}

Y Bouchery, Asma Ghaffari, Zied Jemai, Yves Dallery

\section{To cite this version:}

Y Bouchery, Asma Ghaffari, Zied Jemai, Yves Dallery. Including Sustainability Criteria into Inventory Models. 2011. hal-00614656v2

\section{HAL Id: hal-00614656 \\ https://hal-centralesupelec.archives-ouvertes.fr/hal-00614656v2}

Submitted on 25 Aug 2011

HAL is a multi-disciplinary open access archive for the deposit and dissemination of scientific research documents, whether they are published or not. The documents may come from teaching and research institutions in France or abroad, or from public or private research centers.
L'archive ouverte pluridisciplinaire HAL, est destinée au dépôt et à la diffusion de documents scientifiques de niveau recherche, publiés ou non, émanant des établissements d'enseignement et de recherche français ou étrangers, des laboratoires publics ou privés. 
Cahier d'Études et de Recherche / Research Report

Including Sustainability Criteria into Inventory Models

Yann Bouchery, Asma Ghaffari, Zied Jemai and Yves Dallery 


\title{
Including Sustainability Criteria into Inventory Models
}

\author{
Yann BOUCHERY*, Asma GHAFFARI, Zied JEMAI, Yves DALLERY \\ Laboratoire Génie Industriel, Ecole Centrale Paris \\ Grande Voie des Vignes, 92290 Chatenay-Malabry, France
}

July 22,2011

\begin{abstract}
Research on sustainability performance has considerably enriched operations management literature in recent years. However, work with quantitative models is still scarce. This paper thus contributes to revisit classical inventory models by taking sustainability concerns into account. We believe that reducing all aspects of sustainable development to a single objective is not desirable. We thus reformulate the classical economic order quantity model as a multiobjective problem. We propose to refer to this model as the sustainable order quantity model. Then, a multi-echelon extension of the sustainable order quantity model is studied. For both models, the set of efficient solutions (Pareto optimal solutions) is analytically characterized. These results are used to provide some insights about the effectiveness of different regulatory policies to control carbon emissions. We also propose an interactive procedure that allows the decision maker to quickly identify his / her best option among these solutions. The proposed interactive procedure is a new combination of multi-criteria decision analysis techniques.
\end{abstract}

Keywords: Inventory, sustainable supply chains, multiobjective optimization, interactive procedure.

Acknowledgements: The author would like to express their gratitude to Vincent Mousseau for his helpful comments.

* Corresponding author, Yann Bouchery, yann.bouchery@ecp.fr, Tel: +33 141131210 Fax: +331 41131272 


\section{Introduction}

Sustainable development (SD) is becoming a key issue for companies worldwide. Facing governments, customers and other stakeholders' pressures, the firms are undertaking initiatives to reduce their environmental and social impacts while continuing to be profitable. Following this trend, the literature dealing with SD and operations is becoming abundant (Linton et al., 2007; Carter and Rogers, 2008; Kleindorfer et al., 2005; Seuring and Müller, 2008). However, the papers dealing with quantitative models have up to now mainly focused on reverse and closed-loop logistics or on waste management (Sbihi and Eglese, 2007). We are interested here in investigating the potential of optimizing operations with SD concerns. Operations management decisions can be classified into three levels, i.e. strategic, tactical and operational. Although sustainable supply chains have to be considered globally, researchers and practitioners lack of clear guidelines on how to allocate efforts between these three decision levels (Carter and Rogers, 2008). This paper focuses on the operational level for two reasons. First, operational adjustments are effective to improve the sustainability of supply chains (Benjaafar et al., 2010). Second, operational decisions can be easily adjusted in connection with the other decision levels if needed.

This paper aims at including SD criteria into inventory models. The related literature is quite limited and has mainly focused on carbon footprint. Venkat (2007) considers a two-echelon serial system and studies the impact of batch size in terms of carbon emissions. Two main conclusions are presented. First, frequent deliveries of small batches can increase the carbon footprint of the supply chain if the distances are important. Second, carbon emissions associated with the storage of products that require refrigeration can counterbalance the advantages of full truck-load deliveries. Benjaafar et al. (2010) incorporate carbon emission constraints on single and multi-stage lot-sizing models with a cost minimization objective. Four regulatory policy settings are considered, based respectively on a strict carbon cap, a tax on the amount of emissions, the cap-and-trade system and the possibility to invest on carbon offsets to mitigate carbon caps. Bonney and Jaber (2011) propose to include vehicle emissions cost into the economic order quantity (EOQ) model. The authors refer to this model as the environmental economic order quantity. Emissions associated with the storage of products are not taken into account. The order quantity is thus larger than the classical EOQ. Hua et al. (2011) extend the EOQ model to take carbon emissions into account under the cap and trade system. Analytical and numerical results are complementary to those of Benjaafar et al. (2010). Finally, Arslan and Turkay (2010) include carbon emissions and working hours into the EOQ model. The four regulatory policies studied in Benjaafar et al. (2010) are considered. Moreover, the authors study the case where the carbon footprint is treated as an additional source of economic cost. 
Except Venkat (2007) who does not consider the cost, these papers can be classified as a regulation based integration of SD (or its restriction to carbon footprint) into inventory models. The insights drawn are relevant and much more work can be done in this direction. However, the regulation is not the only green pressure for companies. Firms indeed are becoming increasingly proactive with respect to SD. The concept of SD popularized by Bruntland's report (WCED, 1987) was initially seen as an answer to the resource depletion problem. The United Nations and national governments have been the driving force behind SD, and a lot of companies were first reluctant to include SD concerns into their business model. Firms were mainly convinced that SD issues would erode their competitiveness. The situation has evolved in the nineties and the link between sustainability and profitability became a true debate (Porter and Van der Linde, 1995). Nowadays, even though this question remains open in the literature, more and more consumers are becoming aware of SD issues (Wakeland et al., 2009; Blengini and Shields, 2010). Firms thus seek to get competitive advantage by selling greener products. This trend is reflected in a 2008 survey of 40 chief executive officers from many of the largest third-party logistics industries worldwide (Lieb and Lieb, 2010). In order of importance, the top three reasons to establish sustainability programs were "The corporate desire to do the right thing", "The pressure from customers" and "The corporate desire to enhance company image". Another recent survey of 582 European companies highlights that the regulation is no longer considered as the most important reason to establish sustainability programs (BearingPoint, 2010-2011). In order to reflect this trend, another way to include sustainability criteria into inventory models should be studied.

We believe that reducing all aspects of sustainability to a single objective is not desirable. This paper then adopts the concept of strong sustainability (Neumayer, 2003). We thus study a multiobjective formulation of the EOQ model. We propose to refer to this model as the sustainable order quantity (SOQ) model. A multi-echelon extension of the SOQ model is then studied. For both models, the set of efficient solutions (Pareto optimal solutions) is analytically identified. However, the study of all these solutions can become too time-consuming in practice, especially in an operational context where decisions may be taken several times a day. In this setting, the decision process should quickly end up with a unique solution. We thus propose an interactive multiobjective optimization procedure that enables the firm to provide preference information about economic, environmental and social tradeoffs in order to quickly identify a satisfactory solution. Our contribution is thus threefold. First we propose an innovative way to include SD criteria into inventory models. Second, the multiobjective optimization of the two models studied enables interesting insights to be drawn. Finally, the proposed interactive procedure enables to implement the models in practice as a satisfactory solution is quickly identified. 
The paper is organized as follows. The proposed interactive procedure is presented in section 2 after a review of the related theoretical background. In section 3, the multiobjective formulation of the EOQ model is presented. Analytical multiobjective optimization results and insights are presented. Finally, an extension of the SOQ model to the multi-echelon case is studied in section 4.

\section{A new interactive procedure to identify a satisfactory solution}

\subsection{Theoretical background}

Methods developed for multiobjective optimization problems can be classified into four classes i.e. nopreference methods, a priori methods, a posteriori methods and interactive methods, depending on the role of the decision maker (DM) in the solution process (Miettinen, 1999). The method proposed in this paper belongs to the latter class. In interactive methods, the preference information obtained from the $\mathrm{DM}$ is used to direct the solution process and only a subset of solutions is generated and evaluated. Solving a multiobjective optimization problem interactively is a constructive process consisting of several iterations where the DM builds a conviction of what is possible and confronts this knowledge with his / her preferences that may also evolve. In this setting, the most important stopping criterion is the DM's conviction that a satisfactory solution has been reached. (Miettinen et al., 2008).

In this paper, a non empty set of alternatives (operational decisions) $A$ is evaluated on a family of $n$ criteria $C_{1} ; C_{2} ; \ldots ; C_{n}$ with $C_{i}: A \rightarrow \Re \quad \forall i \in[1, n]$ (the symbol $\forall$ corresponds to "for all"). We assume that the criteria represent SD impacts that should be minimized. An alternative $a \in A$ is said to be dominated if $\exists b \in A$ so that $\forall i \in[1, n], C_{i}(b) \leq C_{i}(a)$ with at least one strict inequality (the symbol $\exists$ corresponds to "there exists"). The non-dominated solutions are called efficient solutions (Pareto optimal solutions) and the set of efficient solutions is called the efficient frontier.

To be able to rank the different alternatives of $A$, an aggregation model is constructed on the basis of preference information provided by the DM. This aggregation model is called preference model. The preference model considered in this paper is in the form of an additive value function $V: A \rightarrow \Re$, such that $\forall a \in A$,

$V(a)=\sum_{i=1}^{n} v_{i}\left(C_{i}(a)\right)$

where $v_{i}$ are monotone decreasing marginal value functions, $v_{i}: \Re \rightarrow \Re, \forall i \in[1, n]$ (Keeney and Raiffa, 1976). The higher is $V(a)$, the better is alternative $a$ for the DM. One possible way to elicit such a preference model is to directly ask the DM for some parameters of the targeted value function. 
Another approach consists in deducing value functions that are compatible with preference information given by the DM. In this second approach known as the preference disaggregation paradigm (JacquetLagrèze and Siskos, 1982), a finite subset of $A$ called the learning set $A_{L}$ is proposed to the DM who is required to compare some alternatives of $A_{L}$. This approach allows the DM to gain more insights about his / her own preferences and a better knowledge of the problem. Furthermore, judgments on alternatives are acknowledged as less demanding in terms of cognitive effort. The main difficulty encountered when using preference disaggregation is that several value functions are often compatible with the information obtained from the DM. The available methods can then be classified into two classes, depending on how they handle the multiplicity of compatible value functions. The first one includes UTA-GMS (Greco et al., 2008a) and GRIP (Figueira et al., 2009). These methods seek for robust conclusions that would be in agreement with all the value functions compatible with the preference information obtained from the DM. The second class of methods using a particular value function is known as meta-UTA techniques (Siskos et al., 2005; Jacquet-Lagrèze and Siskos, 2001). The available methods are UTA* (Siskos and Yannacopoulos, 1985), UTAMP I (Beuthe and Scannella, 1996), UTAMP II (Beuthe and Scannella, 2001) and ACUTA (Bous et al., 2010). Figueira et al. (2008a) also propose a method for selecting the "most representative" value function in the GRIP framework.

Combining preference disaggregation and interactive methods is not a new idea. Jacquet-Lagrèze et al. (1987) propose a method that optimizes an additive value function, which has been interactively assessed, to focus on a particular alternative of $A$. However, this method does not allow the DM to learn about the problem as the value function assessment is the unique interactive phase. Stewart (1987) proposes an interactive method for the progressive elimination of elements from a finite set of alternatives. In this method, the set of utility functions compatible with the preference information given by the DM is used to eliminate elements of $A$. Siskos and Despotis (1989) use UTA to select a value function that is optimized on a feasible region defined at each iteration on the basis of satisfaction levels. Figueira et al. (2008b) present an interactive procedure where GRIP is used to build a set of additive value functions compatible with the preference information obtained from the DM. This set is applied on $A$ to deduce necessary and possible rankings that will help the DM to either select a solution or give new preference information.

The proposed interactive procedure combines the idea of Jacquet-Lagrèze et al. (1987) consisting in optimizing a particular additive value function to focus on a "new" solution with the interactive methodology proposed by Figueira et al. (2008b). The next section describes the proposed interactive procedure. 


\subsection{The proposed interactive procedure}

In this section, we propose an interactive procedure aiming at quickly identify a solution that is satisfactory for the DM. The study of all efficient solutions can indeed be too time-consuming in practice, especially in an operational context where decisions may be taken several times a day. In this context, it can then be useful to start with a rather small but representative learning set and to present a "new" interesting solution to the DM. Our interactive procedure is based on this idea and consists of a number of iterations. At each iteration, a value function reflecting the preference information given by the DM is obtained by using the preference disaggregation approach. This value function is then optimized on $A$ to highlight a "new" solution that is proposed to the DM. The procedure stops when a satisfactory solution is found. The proposed interactive procedure is described in Figure 1.

Figure 1

The proposed interactive procedure

Program

$\underline{\mathrm{DM}}$

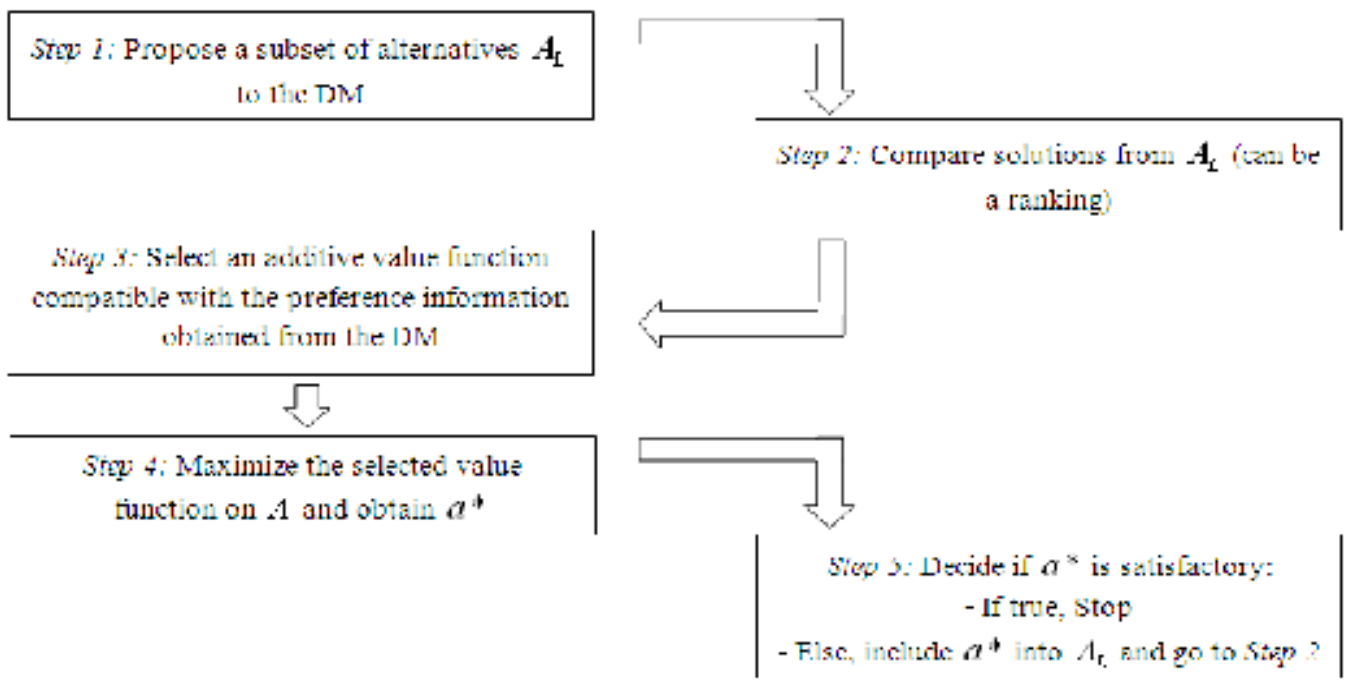

This interactive procedure allows the DM to learn about the problem and make conviction of what is possible as a "new" solution $a^{*}$ is presented at each iteration. It also enables the DM to have evolving preferences while learning about the problem as he / she can come back to the preference information given in Step 2. Moreover, the generated value function is not required to perfectly represent DM's preferences as it is only used to point out a possibly interesting solution $a^{*}$. If the "new" solution is judged unsatisfying, new preference information in relation with $a^{*}$ can be given and a new value function can be generated.

The proposed procedure is compatible with any meta-UTA techniques. In what follows, we decide to use the ACUTA method (Bous et al., 2010). In ACUTA, the value function is selected by computing the analytic center of the feasible value functions polyhedron. This definition is implicit and ensures uniqueness. Being situated "as far as possible" from the boundaries of the feasible value functions" polyhedron, the solution may also be considered as representative. There is however no guarantee that 
the selected value function perfectly represents DM's preferences. As already explained, the procedure enables the DM to either validate or reject the result. Note that the computation of the analytic center is not a linear problem. However, computations were performed using the Diviz software platform (Consortium Decision Deck, 2006-2010) and computation time remains reasonable in all of our experiments.

\subsection{Discussion}

Before presenting the SOQ model and applying the proposed procedure in an example, some general comments on the method can be made.

As already mentioned, several value functions are generally compatible with the preference information obtained from the DM. In the proposed interactive procedure, a specific one is chosen without any validation by the DM. We have indeed argued that this value function is only used to point out a possibly interesting solution. Instead of validating the preference model, the DM can either validate or reject the solution found by optimizing a specific value function. Another method is proposed by Stewart (1987) where the optimality of every alternative in $A$ is checked for every utility function compatible with the preference information obtained from the DM. If the optimality of an alternative is inconsistent in every case, this one is eliminated. In this method, a non eliminated alternative is randomly added to $A_{L}$ and the DM is asked to indicate preference information in relation with this new element. However, the work of Stewart (1987) is limited to the case where $A$ is finite. As it will be shown in the following models, operational decision problems are often characterized by an infinite decision space. Moreover, the interactive method of Stewart (1987) does not allow the DM to have evolving preferences. On the opposite, our procedure enables the DM to come back to the preference information given in Step 2.

It may also happen that the preference information obtained from the DM in Step 2 leads to an empty set of compatible value functions. In this case, two options can be considered. Either the DM can reduce the number of pairwise comparisons made by focusing on the ones he / she is more comfortable with. Doing so, the problem of finding a compatible value function will be less constrained. Or it can be concluded that the DM's preferences are not compatible with an additive value function model. The proposed algorithm is also compatible with non-additive value function models. For instance, Angilella et al. (2004) propose a preference disaggregation method for non-additive value functions.

In our procedure, the appropriateness of the result is deeply influenced by the selection of the learning set in Step 1. The learning set should not contain too many alternatives, and, on the other hand, it 
should be representative enough of the problem. The problem of selecting the most appropriate learning set may deserve future research. However, the proposed procedure can be easily modified to make the learning set denser in the region of the proposed solution $a^{*}$. Instead of presenting only one solution to the DM at each iteration, some solutions in the neighborhood of $a^{*}$ can also be proposed. We will nevertheless focus on the procedure proposed in Figure 1 in what follows.

The procedure can also take strict caps on some criteria into account. In this case, it can be assumed that the additive value function generated in Step 3 represents DM's preferences under reasonable limits. The learning set can be restricted to alternatives that respect the caps and the limitations can be added to the optimization problem in Step 4 by using constraints.

The next sections are devoted to the study of the SOQ model and to an extension of this model in the multi-echelon case.

\section{The sustainable order quantity model}

\subsection{Including SD criteria into the EOQ model}

The EOQ model was first developed by Harris (1913) even if Wilson (1934) is also recognized in connection with this model. Assuming a constant and continuous demand, a fixed leadtime and no shortage allowed, the average total cost per time unit has the following expression:

$C(Q)=P D+\frac{Q}{2} h+\frac{D}{Q} O$,

with:

$Q=$ batch quantity (decision variable),

$P=$ fixed purchase cost per product unit,

$D=$ demand per time unit,

$h=$ constant inventory holding cost per product unit and time unit,

$O=$ fixed ordering or setup cost.

As the cost function $C$ is strictly convex for $Q \in \mathfrak{R}_{+}^{*}$, the optimal batch quantity has the following expression:

$Q^{*}=\sqrt{\frac{2 O D}{h}}$.

It can be noticed that the value $P$ does not affect the optimal order quantity. This parameter will thus be omitted in what follows. 
Considering that minimizing the cost may not be the unique company objective, environmental and social objectives will be included into the model. We refer to this multiobjective extension of the EOQ model as the SOQ model. Determining the set of indicators that appropriately reflects the sustainable performances of operations is beyond the scope of this paper. Note that Bouchery et al. (2010) propose a methodology to build sustainable key performance indicators (KPIs) for distribution supply chains. A set of such KPIs for delivery and warehousing processes is also suggested.

From a general point of view, environmental and social impacts can be associated with both ordering and warehousing operations. A structure similar to Formula 2 is commonly used in the literature to quantify SD impacts (Benjaafar et al., 2010; Arslan and Turkay, 2010; Hua et al., 2011). Let $n$ be the number of criteria $\left(n \in \mathfrak{\aleph}^{*}\right)$. In this paper, each economic, environmental or social impact $C_{i}$ is thus evaluated by using the following formula:

$C_{i}(Q)=\frac{Q}{2} h_{i}+\frac{D}{Q} O_{i}, \forall i \in[1, n]$,

with:

$h_{i}, i \in[1, n]=$ constant inventory holding impact per product unit and time unit pertaining to criteria $i$ $O_{i}, i \in[1, n]=$ fixed ordering impact pertaining to criteria $i$.

In the decision space, the set of possible values for $Q$ is $A=\mathfrak{R}_{+}^{*}$. Let $C: A \rightarrow \mathfrak{R}^{n}$, $C(a)=\left\{C_{1}(a) ; \ldots ; C_{n}(a)\right\}, \quad \forall a \in A, \quad$ with $\quad C_{i} \quad$ defined by Formula $4, \quad \forall i \in[1, n]$. $A^{C}=C(A)=\left\{\left(C_{1}(Q), \ldots, C_{n}(Q)\right) \mid Q \in A\right\}$ is the image of $A$ in the criterion space (evaluation space). From a practical point of view, some alternatives of $A$ are out of interest for the DM as it exists other alternatives that have lower impacts in every criterion. We will analytically determine the efficient frontier $E$ of the SOQ model and derive some properties of its image $E^{C}=C(E)$ in the criterion space. We also introduce the following notations:

- $\mathfrak{R}_{+}^{n}=\left\{\left(x_{1}, \ldots, x_{n}\right) \mid x_{i} \in \mathfrak{R}_{+}, \forall i \in[1, n]\right\}$ is the nonnegative orthant of $\mathfrak{R}^{n}$,

- Let $S_{1}$ and $S_{2}$ two subsets of $\Re^{n}:\left(S_{1}+S_{2}\right)=\left\{S_{1}+s_{2} \mid s_{1} \in S_{1}, s_{2} \in S_{2}\right\}$ is the Minkowski sum, - $E_{+}^{C}=\left(E^{C}+\Re_{+}^{n}\right)$, see Figure 3 for a graphical example.

As $C_{i}(Q)$ is strictly convex for $Q \in \Re_{+}^{*}, \forall i \in[1, n]$, the single objective minimum is expressed as follows:

$Q_{i}^{*}=\sqrt{\frac{2 O_{i} D}{h_{i}}}$. 
We can assume without lack of generality that the criteria are arranged so that $Q_{1}^{*} \leq \ldots \leq Q_{n}^{*}$.

Theorem 1. Let $E$ be the efficient frontier of the SOQ problem and $E^{C}$ its image in the criterion space, then:

- $E=\left[Q_{1}^{*}, Q_{n}^{*}\right]$,

- $E_{+}^{C}$ is convex.

Proofs from here onwards are provided in Appendix A. Note that Theorem 1 is valid as soon as $C$ is a general strictly convex function. We propose to illustrate the results with two criteria $(n=2)$, for instance the cost and the carbon footprint. As an example, let $D=20$ product units per time unit, $O_{\cos t}=O_{1}=50, h_{\cos t}=h_{1}=1.5, O_{\text {emissions }}=O_{2}=200$ and $h_{\text {emissions }}=h_{2}=0.4$. It can be noticed that the parameters' units are omitted. Indeed, they are not useful as only the ratios $O_{i} / h_{i}$ matter. The parameters must nevertheless be expressed with the same unit within a criterion. Applying Formula (5), we get $Q_{1}^{*} \approx 37$ and $Q_{2}^{*} \approx 141$. Figure 2 illustrate the results.

Figure 2

Cost and carbon emissions in function of the batch size

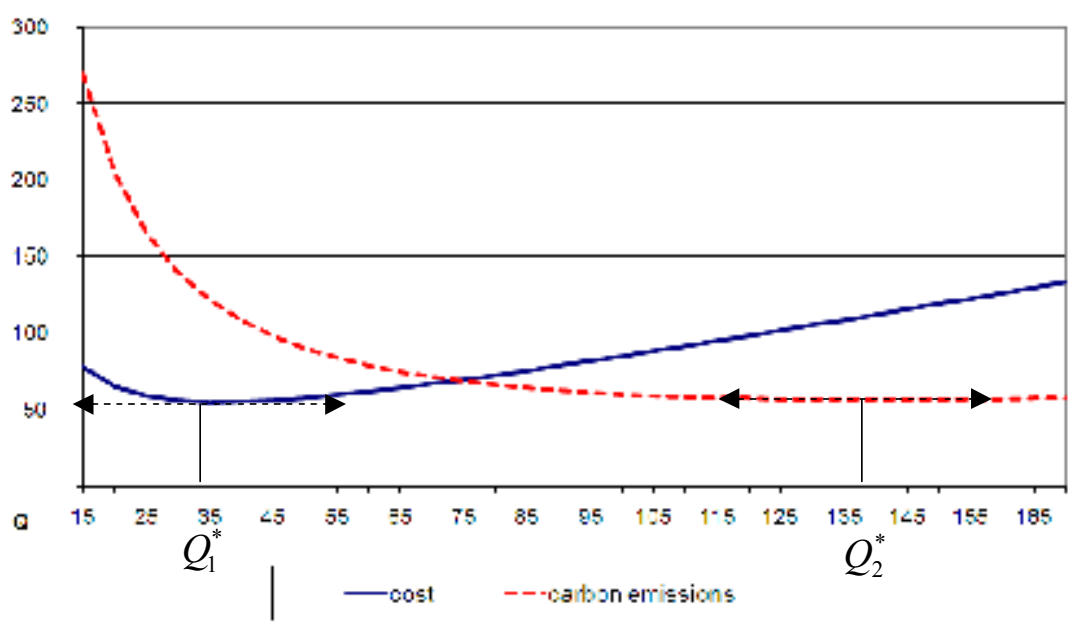

By applying Theorem 1, we obtain that $E=[37 ; 141]$. The image of the efficient frontier is illustrated in Figure 3. This example will be used to discuss the effectiveness of different regulatory policies to control carbon emissions.

First, it can be noticed that a significant carbon emissions reduction can be achieved by operational adjustment while requiring a reasonable financial effort. In this example, the carbon emissions can be reduced by $22 \%$ for a $5 \%$ cost increase starting from the minimal cost. This highlights that operational adjustments are effective to improve the sustainability of supply chains. On the contrary, the financial effort will increase as getting closer to the minimum amount of emissions. In this case, the firms will tend to invest in carbon-reducing technologies in addition to operational adjustments. 
Figure 3

The image of the efficient frontier in the criterion space

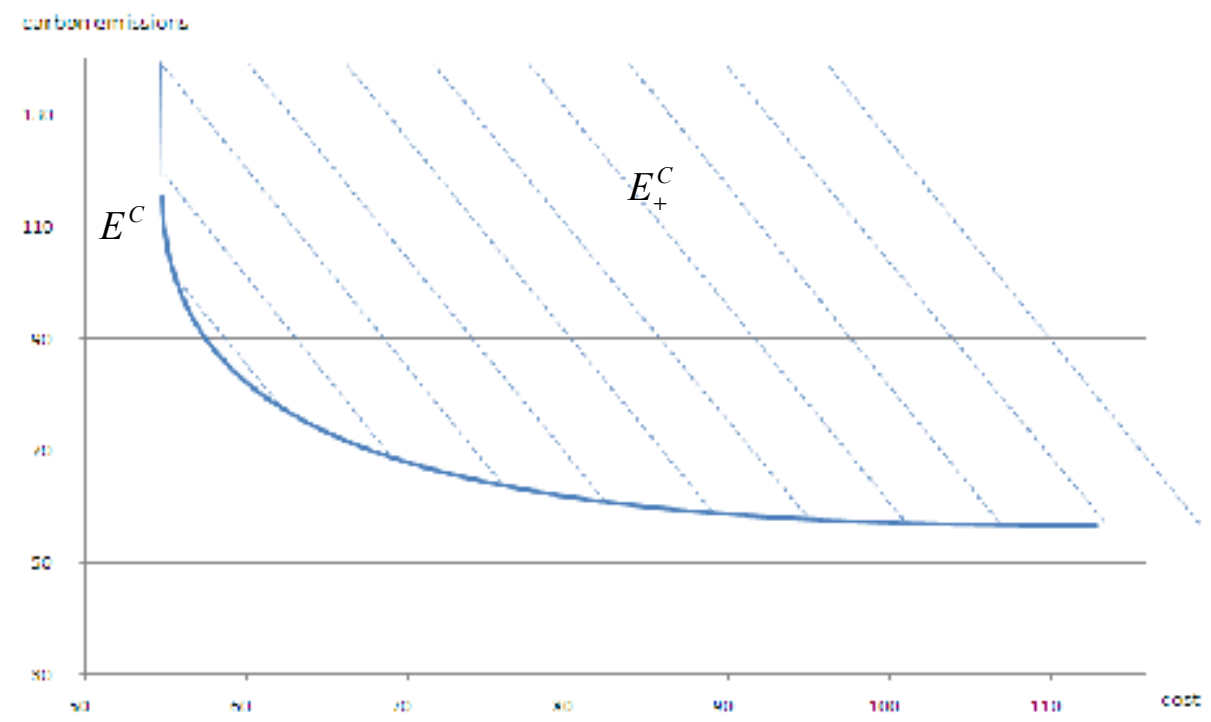

When focusing on regulatory policies, two decisions must be taken. First, policy makers should identify the most effective regulation policy. Second, companies have to react by optimizing their supply chains. Hua et al. (2011) and Benjaafar et al. (2010) have proven that emissions levels depend on the carbon price for the cap and trade system with a fixed carbon price. This is also the case for the carbon tax policy. For these two regulatory policies, the minimum amount of emissions cannot be achieved as it would imply an infinite carbon price.

Moreover, companies will have two possibilities to optimize their supply chains when facing a given carbon price. Companies can indeed make operational adjustments but they can also invest in carbonreducing technologies. The different options are not equivalent in terms of emissions. For a given carbon price, the amount of carbon emissions is thus quite unpredictable. It can then be concluded that the carbon tax policy and the cap and trade system are not very effective in controlling carbon emissions, even if establishing these regulatory policies enables reducing emissions. On the other hand, strict caps are more appropriate to control carbon emissions.

In the next section, a numerical example is given in order to illustrate the type of interaction and the type of result that the interactive procedure proposed in section 2.2 can produce for the SOQ model.

\subsection{Applying the proposed interative procedure to the SOQ model}

In this example, three criteria are taken into account for the SOQ model. We do not advocate that the proposed criteria are the most relevant ones but they are proposed as an example. As greenhouse gases reduction is nowadays a key issue, we decide to choose the carbon footprint as an environmental criterion. The fixed amount of carbon emissions per order represents the emissions related to order 
processing and transportation. An amount of carbon emissions can also be associated with the storage of each unit per time unit. The social dimension of SD has received less attention in the literature (White and Lee, 2009). There is a lack of consensus on how to assess the social performance of operations. In this example, we propose to use the injury rate as a social criterion. Injuries are indeed a major social impact of operations and are caused both by ordering and warehousing operations. For the numerical calculation, the chosen values are presented below.

Table 1

Example parameter's values

demand rate $(\mathrm{D})$

\begin{tabular}{ccccccc} 
ordering cost $\left(\mathrm{O}_{1}\right)$ & 100 & ordering carbon footprint $\left(\mathrm{O}_{2}\right)$ & 320 & ordering injury rate $\left(\mathrm{O}_{3}\right)$ & 119 \\
holding cost $\left(\mathrm{h}_{1}\right)$ & 1 & holding carbon footprint $\left(\mathrm{h}_{2}\right)$ & 0.45 & holding injury rate $\left(\mathrm{h}_{3}\right)$ & 0.27 \\
\hline
\end{tabular}

Applying Formula 5, the three single objective optima can be calculated (see Table 2).

Table 2

Single objective optima

\begin{tabular}{ccccc}
\hline & $Q_{i}^{*}$ & Cost $C_{1}$ & Carbon Emissions $C_{2}$ & Injuries $C_{3}$ \\
\hline economic order quantity & 71 & 70.7 & 128.7 & 51.5 \\
social order quantity & 148 & 90.9 & 87.4 & 40.1 \\
environmental order quantity & 189 & 107.7 & 84.9 & 41.3 \\
\hline
\end{tabular}

Applying Theorem 1, the efficient frontier consists of any batch sizes between [71; 189]. The range on each criterion also appears in Table 2. The final solution will depend on the relative importance the DM gives to each of the three criteria. For this didactic example, we will imagine an interaction with a fictitious DM so as to illustrate the type of interaction and the type of result that the proposed method can produce. Only the images of the alternatives in the criterion space are presented to the DM.

\section{Iteration 1:}

Step 1: We decide to include the three single objective optima ( $a_{1}, a_{3}$ and $a_{5}$ respectively) as well as two other solutions into the learning set (see Table 3).

Table 3

The initial learning set

\begin{tabular}{cccc}
\hline & Cost $C_{1}$ & Carbon emissions $C_{2}$ & Injuries $C_{3}$ \\
\hline $\mathrm{a}_{1}$ & 70.7 & 128.7 & 51.5 \\
$\mathrm{a}_{2}$ & 77.7 & 97.5 & 41.9 \\
$\mathrm{a}_{3}$ & 90.9 & 87.4 & 40.1 \\
$\mathrm{a}_{4}$ & 99.3 & 85.4 & 40.4 \\
$\mathrm{a}_{5}$ & 107.7 & 84.9 & 41.3 \\
\hline
\end{tabular}

Step 2: Assume that the DM provides the following preference information: $a_{2} \mathrm{f} a_{4} \mathrm{f} a_{1}$ ( $f$ corresponds to strict preference). 
Step 3: ACUTA is used with the provided preference information to compute a compatible value function:

$V(Q)=\sum_{i=1}^{3} v_{i}\left(C_{i}(Q)\right)$

Step 4: $V(Q)$ can then be maximized. The optimum is found for $Q=120$, the corresponding alternative is $a_{6}(80.8 ; 93.7 ; 41.0)$.

Step 5: The DM may consider that $a_{6}$ is not satisfactory, this one is added to $A_{L}$.

\section{Iteration 2:}

Step 2: The DM may provide the following additional information: $a_{2} f a_{6} f a_{4} f a_{1}$.

Steps 3 and 4: With this new information, a new value function can be generated and optimized. The optimum is found for $Q=102$, the corresponding alternative is $a_{7}(75.5 ; 101.4 ; 42.9)$.

Step 5: The DM may consider that $a_{7}$ is not satisfactory, this one is added to $A_{L}$.

\section{Iteration 3:}

Step 2: The following preference information may be given by the DM: $a_{2} \mathrm{f} a_{7} \mathrm{f} a_{6} \mathrm{ft} a_{4} \mathrm{f} a_{1}$.

Step 3 and 4: The optimum of the new value function is found for $Q=109$, the corresponding alternative is $a_{8}(77.4 ; 98.0 ; 42.0)$.

Step 5: Assume that the solution $a_{8}$ is satisfactory for the DM, the procedure stops.

It can be noticed that the resulting solution is relatively close to alternative $a_{2}$ which was randomly generated in Step 1. However, the DM feels more confident with alternative $a_{8}$ as he / she has learnt about the problem and about his / her own preferences. The proposed procedure enables an effective interaction with the DM as a satisfactory solution is quickly identified.

The next section is devoted to the sensitivity analysis of the results.

\subsection{Sensitivity analysis}

The previous section has shown that the proposed interactive procedure allows the DM to quickly find a satisfactory solution for the SOQ model. However, this procedure will be used in practice only if it ensures a certain kind of robustness. The following result proves that the procedure is quite insensitive to a slightly change or an estimation error for any parameter of the model. 
Recall that in the SOQ model, $n$ criteria $\left(n \in \mathcal{N}^{*}\right)$ are evaluated by using Formula 4, $C_{i}(Q)=\frac{Q}{2} h_{i}+\frac{D}{Q} O_{i}, \forall i \in[1, n]$. Assume that the value function generated in the last iteration of the proposed interactive procedure represents DM's preferences. This value function is noted $V^{*}(Q)=\sum_{i=1}^{n} v_{i}^{*}\left(C_{i}(Q)\right)$ and is maximal for $Q=Q^{*}$. By using ACUTA, $\forall i \in[1, n], v_{i}^{*}$ is piecewise linear decreasing. The following theorem proves that $V^{*}$ behaves as a cost function $C_{e q}(Q)=\frac{Q}{2} h_{e q}+\frac{D}{Q} O_{e q}$ in a neighborhood of $Q^{*}$, with $h_{e q}=\sum_{i=1}^{n} \alpha_{i} h_{i}$ and $O_{e q}=\sum_{i=1}^{n} \alpha_{i} O_{i}$. It implies that $V^{*}$ has the same robustness as the cost function in the EOQ model.

Theorem 2. There exists $Q_{\min }<Q_{\max } \in \mathfrak{R}_{+}^{*}$ such that:

$$
\begin{aligned}
& -Q^{*} \in\left[Q_{\min }, Q_{\max }\right], \\
& \text { - } \forall Q \in\left[Q_{\min }, Q_{\max }\right], V^{*}\left(Q^{*}\right)-V^{*}(Q)=C_{e q}(Q)-C_{e q}\left(Q^{*}\right) .
\end{aligned}
$$

The coefficients $\alpha_{i}$ can be obtained by using the following formula for $Q \in\left[Q_{\min }, Q_{\max }\right]$ such that $Q \neq Q^{*}:$

$\alpha_{i}=\frac{v_{i}^{*}\left(C_{i}(Q)-C_{i}\left(Q^{*}\right)\right)}{C_{i}(Q)-C_{i}\left(Q^{*}\right)}$.

For $Q \notin\left[Q_{\min }, Q_{\max }\right]$, a deviation appears between $V^{*}\left(Q^{*}\right)-V^{*}(Q)$ and $C_{e q}(Q)-C_{e q}\left(Q^{*}\right)$. Figure 4 illustrates Theorem 2, the chosen value function is the one obtained in iteration 3 of section 3.2.

Figure 4

Illustration of Theorem 2

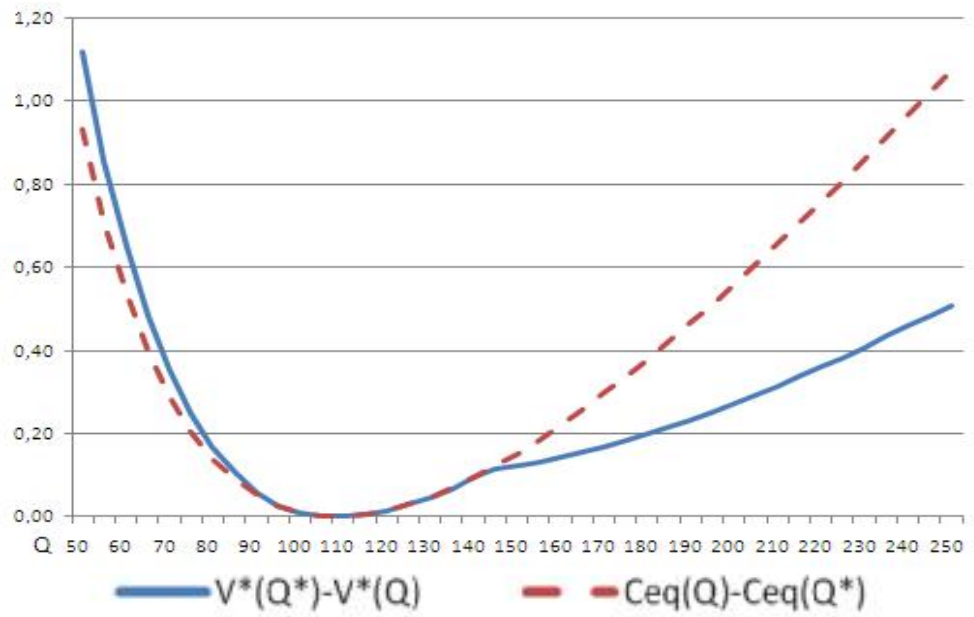

For this example, recall that $Q^{*}=109 . V^{*}$ behaves like an a cost function in the EOQ model for a wide range of values as the segment $\left[Q_{\min }, Q_{\max }\right]$ is equal to $[95,140]$. Note that Theorem 2 also 
implies that $V^{*}$ can be considered as a weighted sum of the criteria in the neighborhood of $Q^{*}$. In this case, the coefficients $\alpha_{i}$ may represent the weights.

\section{The two-echelon serial sustainable order quantity model}

\subsection{Problem presentation and preliminary results}

In this section, an extension of the EOQ model in a multi-echelon case is presented. The considered model is a serial system with 2 echelons, where one warehouse supplies a single retailer (see Figure 5). The model was first studied by Schwarz (1973).

Figure 5

The two-echelon serial system

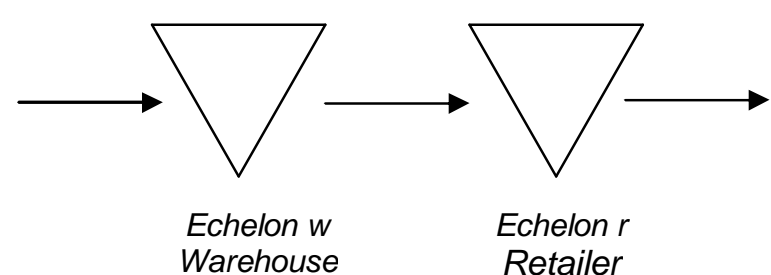

The retailer faces a constant continuous demand. Leadtimes are assumed to be zero for clarity reason (fixed leadtimes can be easily handled) and no shortage is allowed. Moreover, initial inventories are assumed to be zero. Fixed ordering costs and linear holding costs are supported at each location. Let $Q_{r}$ and $Q_{w}$ be the batch quantities ordered by the retailer and by the warehouse respectively. The entire batch is delivered at the same time. The following result is issued from Schwarz (1973).

$\begin{aligned} \text { Preliminary Result. } & \text { An optimal policy is stationary-nested and respects the zero-inventory } \\ & \text { condition i.e.: } \\ & -Q_{r} \text { and } Q_{w} \text { are time invariant, } \\ & -Q_{w}=k \cdot Q_{r}, \text { with } k \in \aleph^{*}, \\ & - \text { The retailer orders only if its inventory level is null, } \\ & \text { - The warehouse orders when both the retailer and the warehouse have no } \\ & \text { inventory. }\end{aligned}$

To simplify the notations, let $Q_{r}=Q$. The total cost can then be expressed in function of $Q$ and $k$ :

$C(k, Q)=\left(h_{r}+(k-1) h_{w}\right) \frac{Q}{2}+\left(O_{r}+\frac{O_{w}}{k}\right) \frac{D}{Q}$,

with:

$Q=$ batch quantity at the retailer (first decision variable), 
$k=$ strictly positive integer such that $Q_{w}=k \cdot Q$ (second decision variable),

$D=$ demand per time unit,

$h_{r}=$ constant inventory holding cost per product unit and time unit at the retailer,

$h_{w}=$ constant inventory holding cost per product unit and time unit at the warehouse,

$O_{r}=$ fixed ordering cost at the retailer,

$O_{w}=$ fixed ordering cost at the warehouse.

If $h_{r}<h_{w}$, the minimum of Formula 8 is found for $k^{*}=1$. Else, let $k^{\mathrm{inf}}=\sqrt{\frac{O_{w}\left(h_{r}-h_{w}\right)}{O_{r} h_{w}}} \cdot k^{*}$ is a strictly positive integer that can be found by using the following rule. If $k^{\text {inf }}<1$, it is optimal to choose $k^{*}=1$. Else, let $k^{\prime} \leq k^{\text {inf }} \leq k^{\prime}+1$ with $k^{\prime} \in \mathfrak{\aleph}^{*}$. If $\frac{k^{\text {inf }}}{k^{\prime}} \leq \frac{k^{\prime}+1}{k^{\text {inf }}}$ then it is optimal to choose $k^{*}=k^{\prime}$.

Otherwise, $k^{*}=k^{\prime}+1$ (Axsäter, 2006). It follows that,

$Q^{*}=\sqrt{\frac{2 D\left(O_{r}+\frac{O_{w}}{k^{*}}\right)}{h_{r}+\left(k^{*}-1\right) h_{w}}}$.

We will now consider the case where several criteria $(n \geq 2)$ have to be taken into account and we refer to this problem as the two-echelon serial SOQ problem. Theorem 3 proves that each efficient ordering policy (efficient solution) can be found in the set of "basic" policies.

Theorem 3. For the two-echelon serial SOQ problem, an ordering policy leading to an efficient solution is basic i.e.:

- The retailer orders only if its inventory level is null,

- The warehouse orders when both the retailer and the warehouse have no inventory.

- All deliveries made to the retailer between successive deliveries to the warehouse are of equal size.

In what follows, we will restrict our attention to stationary policies as non-stationary ones are often too complicated to be implemented in practice. Note that the following results can be extended if nonstationary policies are of interest for the DM. Focusing on stationary policies, preliminary results holds and the simplified notations $Q$ and $k$ are kept. Each SD impact $C_{i}$ is thus evaluated by using the following formula:

$C_{i}(k, Q)=\left(h_{i r}+(k-1) h_{i w}\right) \frac{Q}{2}+\left(O_{i r}+\frac{O_{i w}}{k}\right) \frac{D}{Q}, \forall i \in[1, n]$,

with:

- $h_{i r}, i \in[1, n]:$ constant inventory holding impact $i$ per product unit and time unit at the retailer, 
- $h_{i w}, i \in[1, n]$ : constant inventory holding impact $i$ per product unit and time unit at the warehouse,

- $O_{i r}, i \in[1, n]$ : ordering impact $i$ per order at the retailer,

- $O_{i w}, i \in[1, n]$ : ordering impact $i$ per order at the warehouse.

$\forall i \in[1, n]$, if $h_{i r}<h_{i w}, k_{i}^{*}=1$.Else, $k_{i}^{*}$ is a strictly positive integer that can be found by using the rule described earlier with $k_{i}^{\text {inf }}=\sqrt{\frac{O_{i w}\left(h_{i r}-h_{i w}\right)}{O_{i r} h_{i w}}}, \forall i \in[1, n]$. The minimum of Formula 10 is found for:

$Q_{i}^{*}=\sqrt{\frac{2 D\left(O_{i r}+\frac{O_{i w}}{k_{i}^{*}}\right)}{h_{i r}+\left(k_{i}^{*}-1\right) h_{i w}}}$, and $k_{i}^{*}$ defined above, $\forall i \in[1, n]$.

The next section is devoted to the identification of the efficient frontier of the two-echelon serial SOQ problem.

\subsection{Multiobjective optimization of the two-echelon serial SOQ model}

In this section, some theorems that allow characterizing the efficient frontier of the two-echelon serial SOQ problem are presented. Comparing to the mono-echelon SOQ model, a strictly positive integer $k$ is added as decision variable. Let $n$ be the number of criteria $\left(n \in \mathfrak{N}^{*}\right)$. In the decision space, the set of possible alternatives $A$ is $\left\{(k, Q) \mid k \in \mathfrak{N}^{*}, Q \in \mathfrak{R}_{+}^{*}\right\}$. Let $C: A \rightarrow \mathfrak{R}^{n}, C(a)=\left\{C_{1}(a) ; \ldots ; C_{n}(a)\right\}, \forall a \in A$, with $C_{i}$ defined by Formula 10, $\forall i \in[1, n]$. The image of $A$ in the criterion space is $A^{C}=\left\{\left(C_{1}(k, Q), \ldots, C_{n}(k, Q)\right) \mid(k, Q) \in A\right\}$. Let $E$ be the efficient frontier of the problem and $E^{C}=C(E)$ its image in the criterion space. Moreover, let $E_{+}^{C}=\left(E^{C}+\Re_{+}^{n}\right)$.

We will first consider the case with $k$ fixed. $A_{k}^{C}=\left\{\left(C_{1}(k, Q), \ldots, C_{n}(k, Q)\right) \mid Q \in \mathfrak{R}_{+}^{*}\right\}, \forall k \in \mathfrak{N}^{*}$. The efficient frontier of this sub-problem is noted $E_{k}$ and $E_{k}^{C}$ is its image in the criterion space. Let $E_{k+}^{C}=\left(E_{k}^{C}+\Re_{+}^{n}\right)$. As Formula 11 is strictly convex in $Q$, assume that $Q_{i}^{k^{*}}$ minimizes $C_{i}(k, Q)$.

Theorem 4. Let $E_{k}$ be the efficient frontier of the two-echelon serial SOQ with $k$ fixed and $E_{k}^{C}$ its image in the criterion space, then:

- $E_{k}=\left[\min _{i}\left(Q_{i}^{k^{*}}\right), \max _{i}\left(Q_{i}^{k^{*}}\right)\right]$,

- $E_{k+}^{C}$ is convex. 
It can be noticed that $E^{C} \subset \bigcup_{k=1}^{\infty} E_{k}^{C}$. We could intuitively expect that $E^{C} \subset \bigcup_{k=\min \left(k_{i}^{*}\right)}^{\max \left(k_{i}^{*}\right)} E_{k}^{C}$. However, a counterexample can be found even for $n=2$ (Table 4). Applying Formula 11 to the example presented in Table 4 , we get $k_{1}^{*}=3$ and $k_{2}^{*}=3$. It could then be tempting to conclude that $E^{C}=E_{3}^{C}$. However, some elements of $E_{4}^{C}$ are also efficient. This can be seen in Figure 6. In this example, $E^{C} \subset\left\{E_{3}^{C} \cup E_{4}^{C}\right\}$.

Table 4

Example data set

demand rate $(\mathrm{D})$

holding impact 1 at the retailer $\left(\mathrm{h}_{1 \mathrm{r}}\right)$

holding impact 1 at the warehouse $\left(\mathrm{h}_{1 \mathrm{w}}\right)$

ordering impact 1 at the retailer $\left(\mathrm{O}_{1 \mathrm{r}}\right)$

ordering impact 1 at the warehouse $\left(\mathrm{O}_{1 \mathrm{w}}\right)$
50

10

6

50

500 holding impact 2 at the retailer $\left(\mathrm{h}_{2 \mathrm{r}}\right)$

holding impact 2 at the warehouse $\left(\mathrm{h}_{2 \mathrm{w}}\right) \quad 0.5$

ordering impact 2 at the retailer $\left(\mathrm{O}_{2 \mathrm{r}}\right) \quad 10$

ordering impact 2 at the warehouse $\left(\mathrm{O}_{2 \mathrm{w}}\right) \quad 10$

Figure 6

The example criterion space

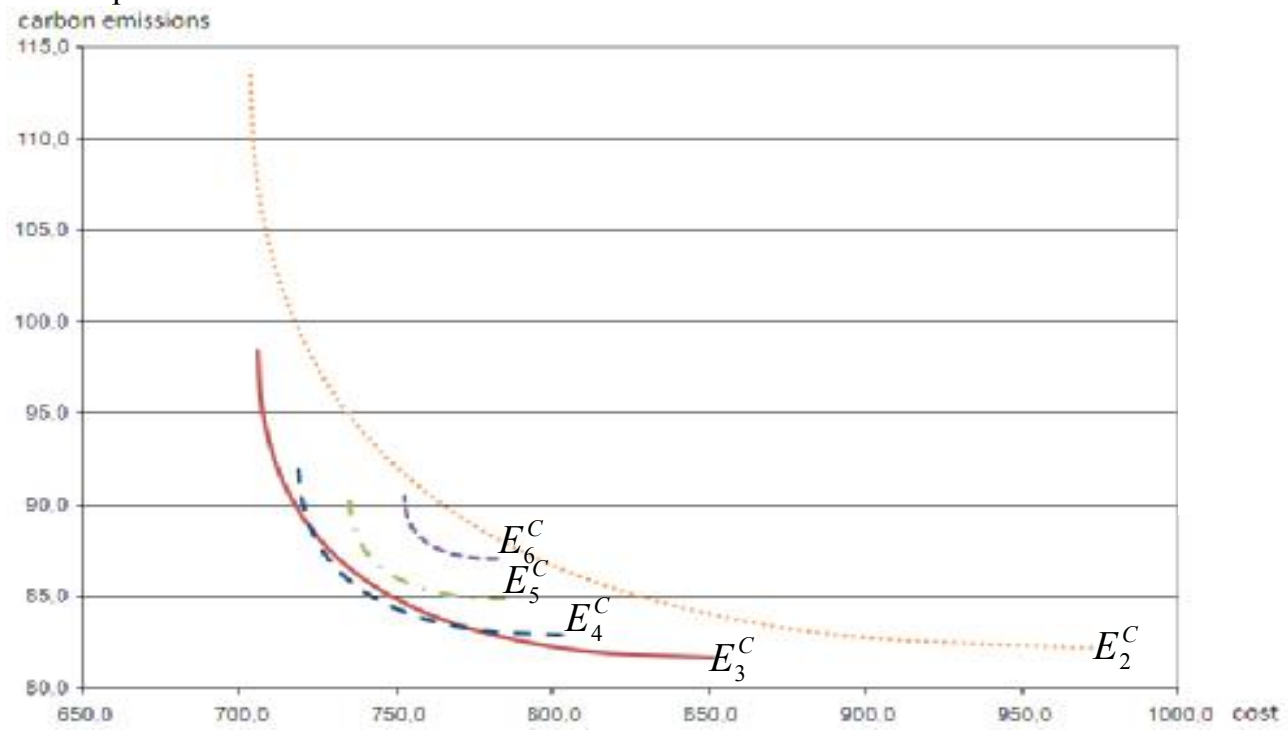

Theorem 5 states that a lower bound $k_{\min }$ and an upper bound $k_{\max }$ exist such that $E^{C} \subset \bigcup_{k=k_{\min }}^{k_{\max }} E_{k}^{C}$.

Theorem 5. There exists $\left(k_{\min }, k_{\max }\right) \in \boldsymbol{\aleph}^{* 2}$ such that:

$$
\begin{aligned}
& -1 \leq k_{\min } \leq \min _{i}\left(k_{i}^{*}\right), \\
& -\max _{i}\left(k_{i}^{*}\right) \leq k_{\max }, \\
& E^{C} \subset \bigcup_{k=k_{\min }}^{k_{\max }} E_{k}^{C} .
\end{aligned}
$$

It can also be noticed in the above example that $E_{+}^{C}$ is non convex. This result can be generalized as soon as $E^{C}$ is not included into a single set $E_{k}^{C}$. This condition necessarily holds when 
$\min _{i}\left(k_{i}^{*}\right) \neq \max _{i}\left(k_{i}^{*}\right)$. However, the example above proves that the reciprocal is not true. This result is stated in Theorem 6 .

Theorem 6. If $\min _{i}\left(k_{i}^{*}\right)<\max _{i}\left(k_{i}^{*}\right)$, then $E_{+}^{C}$ is non convex.

An illustration of the two-echelon serial SOQ problem is given with two criteria (the cost and the carbon footprint). Parameter's value can be found in Table 5.

Table 5

Example data set

demand rate $(\mathrm{D})$

holding impact 1 at the retailer $\left(\mathrm{h}_{1 \mathrm{r}}\right)$

holding impact 1 at the warehouse $\left(\mathrm{h}_{1 \mathrm{w}}\right)$

ordering impact 1 at the retailer $\left(\mathrm{O}_{1 \mathrm{r}}\right)$

ordering impact 1 at the warehouse $\left(\mathrm{O}_{1 \mathrm{w}}\right)$

\section{0}

8

4

80

350 holding impact 2 at the retailer $\left(\mathrm{h}_{2 \mathrm{r}}\right)$

2

holding impact 2 at the warehouse $\left(\mathrm{h}_{2 \mathrm{w}}\right)$

0.15

ordering impact 2 at the retailer $\left(\mathrm{O}_{2 \mathrm{r}}\right)$

45

ordering impact 2 at the warehouse $\left(\mathrm{O}_{2 \mathrm{w}}\right)$

It can be noticed that $E_{+}^{C}$ is non convex in this example (See Figure 7). In this case, some efficient solutions cannot be generated by using a linear combination of the objectives. For instance, $E_{2}^{C} \cap E_{3}^{C}$ is an efficient solution that cannot be found by optimizing a linear combination of the two objectives. However, this solution can represent a desirable compromise for the company. The interactive procedure described in section 2.2 enables proposing such solutions by optimizing an additive value function instead of a simple weighted sum. This strengthens the proposed interactive procedure.

Figure 7

The image of the efficient frontier in the criterion space

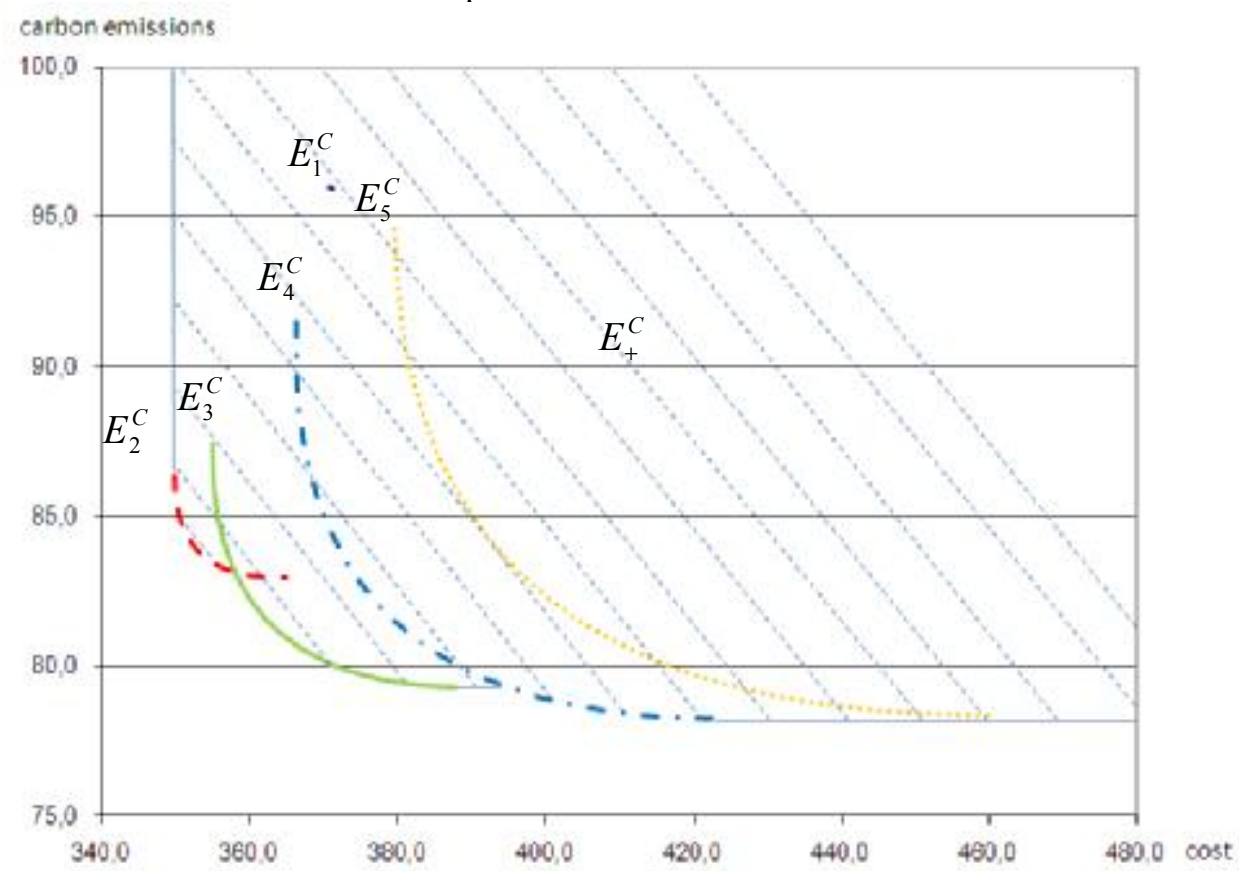


The same interpretation can be done when focusing on the carbon tax. As a traditional carbon tax scheme is a linear one, some operational efficient solutions are ruled out. This problem could be overcome by using non linear tax schemes. The proposed interactive procedure could be used in this case to find a non linear carbon tax function that seems satisfactory for policy makers. The marginal value functions $v_{i}$ can be interpreted as the tax function and could thus be presented to policy makers.

\section{Conclusion}

This paper presents a novel approach for integrating SD criteria into inventory model. In order to consider the different aspects of sustainability, we propose to formulate inventory models as multiobjective problems. We thus consider a multiobjective formulation of the EOQ model called the SOQ model. A multi-echelon extension of the SOQ model is also studied. For both models, the efficient frontier is analytically characterized and the results are used to analyze the effectiveness of different regulatory policies to control carbon emissions. We also propose an interactive procedure that allows the decision maker to quickly identify his / her best option among these solutions.

Further research directions are numerous. First of all, other inventory models could be revisited. The study of more complex models could nevertheless be difficult as optimal solutions are often hard to determine even in the mono-objective case (see e.g. Crowston et al. (1973); Roundy (1985) or Roundy (1986)). In this case, closed to optimal solutions could be used. Other OM decisions could also be revisited by considering the problem as multiobjective. For instance, facilities location, supplier selection and transportation mode selection also affect the sustainability of the supply chain.

An interesting question arises when the DM has to explain his / her choice. The additive value functions selected in the proposed procedure can of course be used to explain the decision. Another interesting research direction could consist in adapting the dominance-based rough set approach proposed in Greco et al. (2008b). In this case, the DM could select a rule that is concordant with the given preference information. This rule could then be added to the model and a new learning set could be generated. This approach could simplify the explanation of the decision.

Finally, operational decisions usually involve more than one DM within a company and more than one company along the supply chain. Research aiming at including SD criteria into inventory models with multiple actors should be conducted. For instance, investigating the impact of collaboration among companies with SD concerns is of major interest. The way to handle the multiplicity of the DMs within a company should also be studied. 


\section{Appendix A}

\section{Proof of Theorem 1:}

Identification of the efficient frontier:

If $Q_{1}^{*}=Q_{n}^{*}, E=Q_{1}^{*}$ as $C_{i}\left(Q_{1}^{*}\right)$ is the unique minimum on each criteria $i$.

Assume that $Q_{1}^{*}<Q_{n}^{*}$ :

- $C_{1}(Q)$ is strictly increasing on $\left[Q_{1}^{*}, Q_{n}^{*}\right]$,

- $C_{n}(Q)$ is strictly decreasing on $\left[Q_{1}^{*}, Q_{n}^{*}\right]$,

- $\forall i \in[1, n], C_{i}(Q)$ is strictly increasing on $\left[Q_{n}^{*}, \infty\right)$ and strictly decreasing on $\left(0, Q_{1}^{*}\right]$ then the solution is dominated if $Q \notin\left[Q_{1}^{*}, Q_{n}^{*}\right]$,

then $E=\left[Q_{1}^{*}, Q_{n}^{*}\right]$.

\section{Convexity:}

As $\Re_{+}^{n}$ is convex, we only have to prove that $\forall(a, b) \in E^{C} \times E^{C}$, the segment $[a, b]$ is included into $E_{+}^{C}$.

Let $(a, b) \in E^{C} \times E^{C}$, if $a=b, a \in E_{+}^{C}$ by definition.

Else, let $a=C\left(Q_{a}\right)$ and $b=C\left(Q_{b}\right)$ with $\left(Q_{a}, Q_{b}\right) \in\left[Q_{1}^{*}, Q_{n}^{*}\right] \times\left[Q_{1}^{*}, Q_{n}^{*}\right]$.

$a \in E_{+}^{C}$ and $b \in E_{+}^{C}$.

$\forall \lambda \in] 0,1\left[\right.$, let $x_{\lambda}=\lambda \cdot a+(1-\lambda) \cdot b$.

As $C$ is strictly convex, $x_{\lambda}$ is dominated by $C\left(\lambda \cdot Q_{a}+(1-\lambda) \cdot Q_{b}\right)$.

So, $x_{\lambda} \in E_{+}^{C}$.

\section{Proof of Theorem 2:}

$v_{i}^{*}$ are piecewise linear decreasing then it exits $\left(Q_{\min }, Q_{\max }\right) \in \mathfrak{R}_{+}^{*} \times \mathfrak{R}_{+}^{*}$ such that:

- $Q^{*} \in\left[Q_{\min }, Q_{\max }\right]$,

- $\forall i \in[1, n]$, it exists $\alpha_{i} \in \mathfrak{R}_{+}^{*} \mid \forall Q \in\left[Q_{\min }, Q_{\max }\right], v_{i} *\left(C_{i}(Q)\right)=v_{i}\left(C_{i}\left(Q^{*}\right)\right)-\alpha_{i}\left(C_{i}(Q)-C_{i}\left(Q^{*}\right)\right)$.

By applying Formula (6), we obtain that $\forall Q \in\left[Q_{\min }, Q_{\max }\right]$ :

$V^{*}(Q)=\sum_{i=1}^{n} v_{i}^{*}\left(C_{i}(Q)\right)=V^{*}\left(Q^{*}\right)+\left(\frac{h_{e q} \cdot Q^{*}}{2}+\frac{O_{e q} \cdot D}{Q^{*}}\right)-\left(\frac{h_{e q} \cdot Q}{2}+\frac{O_{e q} \cdot D}{Q}\right)$, with $h_{e q}=\sum_{i=1}^{n} \alpha_{i} \cdot h_{i}$ and $O_{e q}=\sum_{i=1}^{n} \alpha_{i} \cdot O_{i}$.

It follows that:

$\forall Q \in\left[Q_{\min }, Q_{\max }\right], V^{*}\left(Q^{*}\right)-V^{*}(Q)=C_{e q}(Q)-C_{e q}\left(Q^{*}\right)$.

\section{Proof of Theorem 3: Similar to that of Schwartz (1973)}

(1) The retailer orders only if its inventory level is null:

Consider any feasible policy that does not satisfy (1) at some time t. Every holding impacts in the interval $[0, t]$ will be reduced by reducing the amount of the preceding delivery by the inventory on hand at time $t$ (or to zero) and increasing the amount of the delivery at time $t$ by the same amount. This 
adjustment does not increase the number of deliveries and ordering impacts are thus reduced or kept equal. By repeating this adjustment for every retailer delivery time, a policy satisfying (1) will result.

(2) The warehouse orders when both the retailer and the warehouse have no inventory:

The fact that the warehouse orders when its inventory level is null is proven in the same manner as (1). To prove that the warehouse orders when the retailer has no inventory, we remark that on the other case, the warehouse order can be postponed until the retailer orders. This will decrease every holding impact at the warehouse without modifying the ordering impacts. By applying (1), this condition happens when the inventory at the retailer is null.

(3) All deliveries made to the retailer between successive deliveries to the warehouse are of equal size:

Assume that there are ${ }_{n}$ deliveries to the retailer of lot sizes $Q_{k}, k \in[1, n]$ such that $\sum_{k=1}^{n} Q_{k}=Q$ between any two successive deliveries to the warehouse. The only impacts affected by these lot sizes are the holding impacts at the retailer. As $D$ is constant, the minimum of all holding impacts at the retailer is reached when $\forall k \in[1, n], Q_{k}=\frac{Q}{n}$.

\section{Proof of Theorem 4:}

Similar to that of Theorem 1.

\section{Proof of Theorem 5:}

The existence of $k_{\min }$ is trivial.

Moreover, the mono-objective optima defined in Formula 11 are included in $E$ by definition, then $1 \leq k_{\min } \leq \min _{i}\left(k_{i}^{*}\right)$.

It also implies that if $k_{\max }$ exists, $\max _{i}\left(k_{i}^{*}\right) \leq k_{\max }$.

$\forall i \in[1, n], C_{i}(k, Q)$ tends to infinity as $k$ tends to infinity. Let $e\left(k_{e}, Q_{e}\right) \in E$.

It exits $t \in \mathfrak{\aleph}^{*}$ such that $\forall i \in[1, n], \forall Q \in \mathfrak{R}_{+}^{*}, \forall n \in \mathfrak{\aleph}, C_{i}\left(k_{e}, Q_{e}\right)<C_{i}(t+n, Q)$.

Then $e$ dominates all elements of $\bigcup_{k=t}^{\infty} E_{k}$. That proves the existence of $k_{\max }$.

\section{Proof of Theorem 6:}

By using Theorem 5, $E^{C} \subset \bigcup_{k=k_{\min }}^{k_{\max }} E_{k}^{C}$.

As $\min _{i}\left(k_{i}^{*}\right)<\max _{i}\left(k_{i}^{*}\right)$, there exists $e_{k_{\min }} \in E_{k_{\min }}^{C} \mid e_{k_{\min }} \in E^{C}$ and $e_{k_{\max }} \in E_{k_{\max }}^{C} \mid e_{k_{\max }} \in E^{C}$.

$E_{\min \left(k_{i}^{*}\right)+}^{C} \neq E_{\max _{i}\left(k_{i}^{*}\right)+}^{C}$ and both are convex by using Theorem 4 thus $E^{C}$ is non convex. 


\section{References}

Angilella, S., Greco, S., Lamantia, F., Matarazzo, B., 2004. Assessing non-additive utility for multicriteria decision aid. European Journal of Operational Research, 158(3), 734-744.

Arslan, M.C., Turkay M., 2010. EOQ Revisited with Sustainability Considerations, working paper.

Axsäter, S., 2006. Inventory control, Springer, New York.

BearingPoint, 4th Supply Chain Monitor, 2010-2011, Available at http://www.bearingpointconsulting.com/de-de/download/TAP-SC EN.pdf, accessed on June $17,2011$.

Benjaafar, S., Li, Y., Daskin, M., 2010. Carbon Footprint and the Management of Supply Chains: Insights from Simple Models, working paper.

Beuthe, M., Scannella, G., 1996. Applications comparées des méthodes d'analyse multicritère UTA. RAIRO Operations Research, 30, 293-315.

Beuthe, M., Scannella, G., 2001. Comparative analysis of UTA multicriteria methods. European Journal of Operational Research, 130, 246-262.

Blengini, G.A., Shields, D.J., 2010. Green Labels and Sustainability Reporting. Management of Environmental Quality: An International Journal, 21(4), 477-493.

Bonney, M., Jaber, M.Y., 2011. Environmentally responsible inventory models: Non-classical models for a non-classical era. International Journal of Production Economics, 133(1), 43-53.

Bouchery, Y., Ghaffari, A., Jemai, Z., 2010. Key Performance Indicators for Sustainable Distribution Supply Chains: Set Building Methodology and Application. Cahiers de recherche 2010-08, Laboratoire Génie Industriel, Ecole Centrale Paris.

Bous, G., Fortemps, P., Glineur, F., Pirlot, M., 2010. ACUTA: A novel method for eliciting additive value functions on the basis of holistic preference statements. European Journal of Operational Research, 206(2), 435-444.

Carter C., Rogers D.S., 2008. A framework of sustainable supply chain management: moving toward new theory. International Journal of Physical Distribution \& Logistics Management, 38(5), $360-387$.

Consortium Decision Deck., 2006-2010. Decision deck: an open-source software platform for mcda methods. Www.decision-deck.org.

Crowston, W.B., Wagner, M., Williams, J.F., 1973. Economic Lot Size Determination in MultiStage Assembly Systems. Management Science, 19(5), 517-527.

Figueira, J.R., Greco, S., Mousseau, V., Slowinski, R., 2008b. Interactive Multiobjective Optimization Using a Set of Additive Value Functions. In: Branke, J. et al., (Eds.): Multiobjective Optimization, Springer, Heidelberg. 
Figueira, J.R., Greco, S., Slowinski, R., 2009. Building a set of additive value functions representing a reference preorder and intensities of preference: GRIP method. European Journal of Operational Research, 195(2), 460-486.

Figueira, J., Greco, S., Slowinski, R.,, 2008a. Identifying the "most representative" value function among all compatible value functions in the GRIP method. In: Communication at the 68th Meeting of the EURO Working Group "Multiple Criteria Decision Aiding”, Chania, Crete, October 2-3.

Greco, S., Matarazzo, B., Słowiński, R., 2008b. Dominance-Based Rough Set Approach to Interactive Multiobjective Optimization. In J. Branke et al., eds. Multiobjective Optimization. Springer Berlin Heidelberg, 121-155.

Greco, S., Mousseau, V., Slowinski, R., 2008a. Ordinal regression revisited: Multiple criteria ranking using a set of additive value functions. European Journal of Operational Research, 191(2), 416-436.

Harris, F.W., 1913. How Many Parts to Make at Once, factory, The Magazine of Management, 10, 135-136, 152.

Hua, G., Cheng, T.C.E., Wang, S., 2011. Managing carbon footprints in inventory management. International Journal of Production Economics, 132(2), 178-185.

Jacquet-Lagrèze, E., Meziani, R., Slowinski, R., 1987. MOLP with an interactive assessment of a piecewise-linear utility function. European Journal of Operational Research, 31(3), 350-357.

Jacquet-Lagreze, E., Siskos, Y., 1982. Assessing a set of additive utility functions for multicriteria decision-making, the UTA method. European Journal of Operational Research, 10(2), 151164.

Jacquet-Lagrèze, E., Siskos, Y., 2001. Preference disaggregation: 20 years of MCDA experience. European Journal of Operational Research, 130(2), 233-245.

Keeney, R.L., Raiffa, H., 1976. Decisions with Multiple Objectives: Preferences and Value Tradeoffs. Willey, New York.

Kleindorfer, P.R., Singhal, K., Van Wassenhove, L.N., 2005. Sustainable Operations Management. Production and Operations Management, 14(4), 482-492.

Lieb, K.J., Lieb, R.C., 2010. Environmental sustainability in the third-party logistics (3PL) industry. International Journal of Physical Distribution \& Logistics Management, 40(7), 524-533.

Linton, J.D., Klassen, R., Jayaraman, V., 2007. Sustainable supply chains: An introduction. Journal of Operations Management, 25(6), 1075-1082.

Miettinen, K., 1999. Nonlinear Multiobjective Optimization. Kluwer Academic Publishers, Boston.

Miettinen, K., Ruiz, F., Wierzbicki, P., 2008. Introduction to Multiobjective Optimization, Interactive Approaches. In: Branke, J. et al., (Eds.): Multiobjective Optimization, Springer, Heidelberg. 
Neumayer, E., 2003. Weak Versus Strong Sustainability: Exploring the Limits of Two Opposing Paradigms. Edward Elgar, Cheltenham, UK.

Porter, M.E., van der Linde, C., 1995. Green and competitive: ending the stalemate. Harvard Business Review, 73(5), 120-134.

Roundy, R., 1985. 98\%-Effective Integer-Ratio Lot-Sizing for One-Warehouse Multi-Retailer Systems. Management Science, 31(11), 1416-1430.²

Roundy, R., 1986. A 98\%-Effective Lot-Sizing Rule for a Multi-Product, Multi-Stage Production / Inventory System. Mathematics of Operations Research, 11(4), 699-727.

Sbihi, A., Eglese, R., 2007. Combinatorial optimization and Green Logistics. 4OR: A Quarterly Journal of Operations Research, 5(2), 99-116.

Schwarz, L.B., 1973. A Simple Continuous Review Deterministic One-Warehouse N-Retailer Inventory Problem. Management Science, 19(5), 555-566.

Seuring, S., Müller, M., 2008. From a literature review to a conceptual framework for sustainable supply chain management. Journal of Cleaner Production, 16(15), 1699-1710.

Siskos, Y., Despotis, D.K., 1989. A DSS oriented method for multiobjective linear programming problems. Decision Support Systems, 5(1), 47-55.

Siskos, Y., Grigoroudis, E., Matsatsinis, N., 2005. UTA methods. In: Figueira, J., Greco, S., Ehrgott, M. (Eds.), Multiple Criteria Decision Analysis: State of the Art Surveys. Springer Verlag, Berlin.

Siskos, Y., Yannacopoulos, D., 1985. UTASTAR: an ordinal regression method for building additive value functions. Investigaç ao Operacional, 5, 39-53.

Stewart, T., 1987. Pruning of decision alternatives in multiple criteria decision making, based on the UTA method for estimating utilities. European Journal of Operational Research, 28(1), 7988 .

Venkat K., 2007. Analyzing and optimizing the environmental performance of supply chains. Proceedings of the ACCEE Summer Study on Energy Efficiency in Industry, White Plains, New York, U.S.

Wakeland, W., Sears, L., Venkat, K., 2009. Measuring the Effects of Carbon Footprint Training on Consumers. Sustainability: The Journal of Record, 2(1), 45-52.

White, L., Lee, G.J., 2009. Operational research and sustainable development: Tackling the social dimension. European Journal of Operational Research, 193(3), 683-692.

Wilson, R.H., 1934. A scientific Routine for Stock Control, Harvard Business Review 13, 116-128.

World Commission on Environment and Development, 1987. Our Common Future. Oxford University Press, Oxford. 
Cahier d'Études et de Recherche / Research Report

Including Sustainability Criteria into Inventory Models

Yann Bouchery, Asma Ghaffari, Zied Jemai and Yves Dallery 


\title{
Including Sustainability Criteria into Inventory Models
}

\author{
Yann BOUCHERY*, Asma GHAFFARI, Zied JEMAI, Yves DALLERY \\ Laboratoire Génie Industriel, Ecole Centrale Paris \\ Grande Voie des Vignes, 92290 Chatenay-Malabry, France
}

July 22,2011

\begin{abstract}
Research on sustainability performance has considerably enriched operations management literature in recent years. However, work with quantitative models is still scarce. This paper thus contributes to revisit classical inventory models by taking sustainability concerns into account. We believe that reducing all aspects of sustainable development to a single objective is not desirable. We thus reformulate the classical economic order quantity model as a multiobjective problem. We propose to refer to this model as the sustainable order quantity model. Then, a multi-echelon extension of the sustainable order quantity model is studied. For both models, the set of efficient solutions (Pareto optimal solutions) is analytically characterized. These results are used to provide some insights about the effectiveness of different regulatory policies to control carbon emissions. We also propose an interactive procedure that allows the decision maker to quickly identify his / her best option among these solutions. The proposed interactive procedure is a new combination of multi-criteria decision analysis techniques.
\end{abstract}

Keywords: Inventory, sustainable supply chains, multiobjective optimization, interactive procedure.

Acknowledgements: The author would like to express their gratitude to Vincent Mousseau for his helpful comments.

* Corresponding author, Yann Bouchery, yann.bouchery@ecp.fr, Tel: +33 141131210 Fax: +331 41131272 


\section{Introduction}

Sustainable development (SD) is becoming a key issue for companies worldwide. Facing governments, customers and other stakeholders' pressures, the firms are undertaking initiatives to reduce their environmental and social impacts while continuing to be profitable. Following this trend, the literature dealing with SD and operations is becoming abundant (Linton et al., 2007; Carter and Rogers, 2008; Kleindorfer et al., 2005; Seuring and Müller, 2008). However, the papers dealing with quantitative models have up to now mainly focused on reverse and closed-loop logistics or on waste management (Sbihi and Eglese, 2007). We are interested here in investigating the potential of optimizing operations with SD concerns. Operations management decisions can be classified into three levels, i.e. strategic, tactical and operational. Although sustainable supply chains have to be considered globally, researchers and practitioners lack of clear guidelines on how to allocate efforts between these three decision levels (Carter and Rogers, 2008). This paper focuses on the operational level for two reasons. First, operational adjustments are effective to improve the sustainability of supply chains (Benjaafar et al., 2010). Second, operational decisions can be easily adjusted in connection with the other decision levels if needed.

This paper aims at including SD criteria into inventory models. The related literature is quite limited and has mainly focused on carbon footprint. Venkat (2007) considers a two-echelon serial system and studies the impact of batch size in terms of carbon emissions. Two main conclusions are presented. First, frequent deliveries of small batches can increase the carbon footprint of the supply chain if the distances are important. Second, carbon emissions associated with the storage of products that require refrigeration can counterbalance the advantages of full truck-load deliveries. Benjaafar et al. (2010) incorporate carbon emission constraints on single and multi-stage lot-sizing models with a cost minimization objective. Four regulatory policy settings are considered, based respectively on a strict carbon cap, a tax on the amount of emissions, the cap-and-trade system and the possibility to invest on carbon offsets to mitigate carbon caps. Bonney and Jaber (2011) propose to include vehicle emissions cost into the economic order quantity (EOQ) model. The authors refer to this model as the environmental economic order quantity. Emissions associated with the storage of products are not taken into account. The order quantity is thus larger than the classical EOQ. Hua et al. (2011) extend the EOQ model to take carbon emissions into account under the cap and trade system. Analytical and numerical results are complementary to those of Benjaafar et al. (2010). Finally, Arslan and Turkay (2010) include carbon emissions and working hours into the EOQ model. The four regulatory policies studied in Benjaafar et al. (2010) are considered. Moreover, the authors study the case where the carbon footprint is treated as an additional source of economic cost. 
Except Venkat (2007) who does not consider the cost, these papers can be classified as a regulation based integration of SD (or its restriction to carbon footprint) into inventory models. The insights drawn are relevant and much more work can be done in this direction. However, the regulation is not the only green pressure for companies. Firms indeed are becoming increasingly proactive with respect to SD. The concept of SD popularized by Bruntland's report (WCED, 1987) was initially seen as an answer to the resource depletion problem. The United Nations and national governments have been the driving force behind SD, and a lot of companies were first reluctant to include SD concerns into their business model. Firms were mainly convinced that SD issues would erode their competitiveness. The situation has evolved in the nineties and the link between sustainability and profitability became a true debate (Porter and Van der Linde, 1995). Nowadays, even though this question remains open in the literature, more and more consumers are becoming aware of SD issues (Wakeland et al., 2009; Blengini and Shields, 2010). Firms thus seek to get competitive advantage by selling greener products. This trend is reflected in a 2008 survey of 40 chief executive officers from many of the largest third-party logistics industries worldwide (Lieb and Lieb, 2010). In order of importance, the top three reasons to establish sustainability programs were "The corporate desire to do the right thing", "The pressure from customers" and "The corporate desire to enhance company image". Another recent survey of 582 European companies highlights that the regulation is no longer considered as the most important reason to establish sustainability programs (BearingPoint, 2010-2011). In order to reflect this trend, another way to include sustainability criteria into inventory models should be studied.

We believe that reducing all aspects of sustainability to a single objective is not desirable. This paper then adopts the concept of strong sustainability (Neumayer, 2003). We thus study a multiobjective formulation of the EOQ model. We propose to refer to this model as the sustainable order quantity (SOQ) model. A multi-echelon extension of the SOQ model is then studied. For both models, the set of efficient solutions (Pareto optimal solutions) is analytically identified. However, the study of all these solutions can become too time-consuming in practice, especially in an operational context where decisions may be taken several times a day. In this setting, the decision process should quickly end up with a unique solution. We thus propose an interactive multiobjective optimization procedure that enables the firm to provide preference information about economic, environmental and social tradeoffs in order to quickly identify a satisfactory solution. Our contribution is thus threefold. First we propose an innovative way to include SD criteria into inventory models. Second, the multiobjective optimization of the two models studied enables interesting insights to be drawn. Finally, the proposed interactive procedure enables to implement the models in practice as a satisfactory solution is quickly identified. 
The paper is organized as follows. The proposed interactive procedure is presented in section 2 after a review of the related theoretical background. In section 3, the multiobjective formulation of the EOQ model is presented. Analytical multiobjective optimization results and insights are presented. Finally, an extension of the SOQ model to the multi-echelon case is studied in section 4.

\section{A new interactive procedure to identify a satisfactory solution}

\subsection{Theoretical background}

Methods developed for multiobjective optimization problems can be classified into four classes i.e. nopreference methods, a priori methods, a posteriori methods and interactive methods, depending on the role of the decision maker (DM) in the solution process (Miettinen, 1999). The method proposed in this paper belongs to the latter class. In interactive methods, the preference information obtained from the $\mathrm{DM}$ is used to direct the solution process and only a subset of solutions is generated and evaluated. Solving a multiobjective optimization problem interactively is a constructive process consisting of several iterations where the DM builds a conviction of what is possible and confronts this knowledge with his / her preferences that may also evolve. In this setting, the most important stopping criterion is the DM's conviction that a satisfactory solution has been reached. (Miettinen et al., 2008).

In this paper, a non empty set of alternatives (operational decisions) $A$ is evaluated on a family of $n$ criteria $C_{1} ; C_{2} ; \ldots ; C_{n}$ with $C_{i}: A \rightarrow \Re \quad \forall i \in[1, n]$ (the symbol $\forall$ corresponds to "for all"). We assume that the criteria represent SD impacts that should be minimized. An alternative $a \in A$ is said to be dominated if $\exists b \in A$ so that $\forall i \in[1, n], C_{i}(b) \leq C_{i}(a)$ with at least one strict inequality (the symbol $\exists$ corresponds to "there exists"). The non-dominated solutions are called efficient solutions (Pareto optimal solutions) and the set of efficient solutions is called the efficient frontier.

To be able to rank the different alternatives of $A$, an aggregation model is constructed on the basis of preference information provided by the DM. This aggregation model is called preference model. The preference model considered in this paper is in the form of an additive value function $V: A \rightarrow \Re$, such that $\forall a \in A$,

$V(a)=\sum_{i=1}^{n} v_{i}\left(C_{i}(a)\right)$

where $v_{i}$ are monotone decreasing marginal value functions, $v_{i}: \Re \rightarrow \Re, \forall i \in[1, n]$ (Keeney and Raiffa, 1976). The higher is $V(a)$, the better is alternative $a$ for the DM. One possible way to elicit such a preference model is to directly ask the DM for some parameters of the targeted value function. 
Another approach consists in deducing value functions that are compatible with preference information given by the DM. In this second approach known as the preference disaggregation paradigm (JacquetLagrèze and Siskos, 1982), a finite subset of $A$ called the learning set $A_{L}$ is proposed to the DM who is required to compare some alternatives of $A_{L}$. This approach allows the DM to gain more insights about his / her own preferences and a better knowledge of the problem. Furthermore, judgments on alternatives are acknowledged as less demanding in terms of cognitive effort. The main difficulty encountered when using preference disaggregation is that several value functions are often compatible with the information obtained from the DM. The available methods can then be classified into two classes, depending on how they handle the multiplicity of compatible value functions. The first one includes UTA-GMS (Greco et al., 2008a) and GRIP (Figueira et al., 2009). These methods seek for robust conclusions that would be in agreement with all the value functions compatible with the preference information obtained from the DM. The second class of methods using a particular value function is known as meta-UTA techniques (Siskos et al., 2005; Jacquet-Lagrèze and Siskos, 2001). The available methods are UTA* (Siskos and Yannacopoulos, 1985), UTAMP I (Beuthe and Scannella, 1996), UTAMP II (Beuthe and Scannella, 2001) and ACUTA (Bous et al., 2010). Figueira et al. (2008a) also propose a method for selecting the "most representative" value function in the GRIP framework.

Combining preference disaggregation and interactive methods is not a new idea. Jacquet-Lagrèze et al. (1987) propose a method that optimizes an additive value function, which has been interactively assessed, to focus on a particular alternative of $A$. However, this method does not allow the DM to learn about the problem as the value function assessment is the unique interactive phase. Stewart (1987) proposes an interactive method for the progressive elimination of elements from a finite set of alternatives. In this method, the set of utility functions compatible with the preference information given by the DM is used to eliminate elements of $A$. Siskos and Despotis (1989) use UTA to select a value function that is optimized on a feasible region defined at each iteration on the basis of satisfaction levels. Figueira et al. (2008b) present an interactive procedure where GRIP is used to build a set of additive value functions compatible with the preference information obtained from the DM. This set is applied on $A$ to deduce necessary and possible rankings that will help the DM to either select a solution or give new preference information.

The proposed interactive procedure combines the idea of Jacquet-Lagrèze et al. (1987) consisting in optimizing a particular additive value function to focus on a "new" solution with the interactive methodology proposed by Figueira et al. (2008b). The next section describes the proposed interactive procedure. 


\subsection{The proposed interactive procedure}

In this section, we propose an interactive procedure aiming at quickly identify a solution that is satisfactory for the DM. The study of all efficient solutions can indeed be too time-consuming in practice, especially in an operational context where decisions may be taken several times a day. In this context, it can then be useful to start with a rather small but representative learning set and to present a "new" interesting solution to the DM. Our interactive procedure is based on this idea and consists of a number of iterations. At each iteration, a value function reflecting the preference information given by the DM is obtained by using the preference disaggregation approach. This value function is then optimized on $A$ to highlight a "new" solution that is proposed to the DM. The procedure stops when a satisfactory solution is found. The proposed interactive procedure is described in Figure 1.

Figure 1

The proposed interactive procedure

Program

$\underline{\mathrm{DM}}$

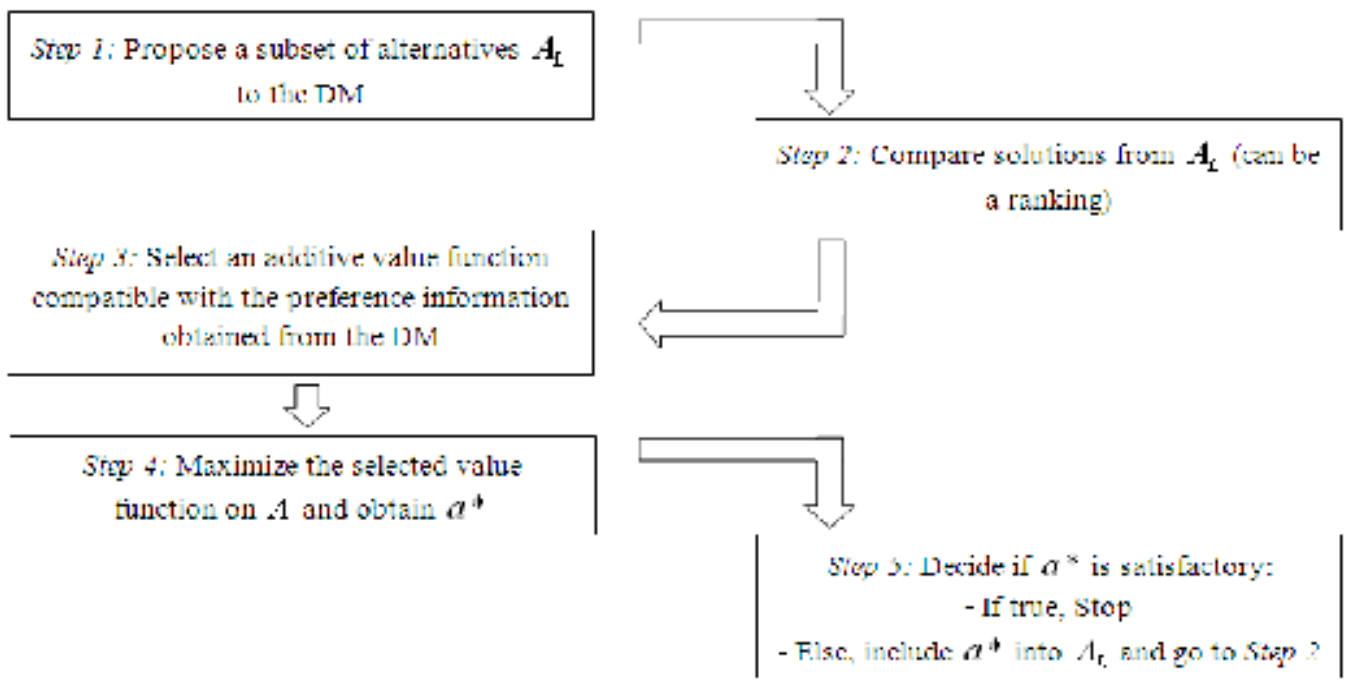

This interactive procedure allows the DM to learn about the problem and make conviction of what is possible as a "new" solution $a^{*}$ is presented at each iteration. It also enables the DM to have evolving preferences while learning about the problem as he / she can come back to the preference information given in Step 2. Moreover, the generated value function is not required to perfectly represent DM's preferences as it is only used to point out a possibly interesting solution $a^{*}$. If the "new" solution is judged unsatisfying, new preference information in relation with $a^{*}$ can be given and a new value function can be generated.

The proposed procedure is compatible with any meta-UTA techniques. In what follows, we decide to use the ACUTA method (Bous et al., 2010). In ACUTA, the value function is selected by computing the analytic center of the feasible value functions polyhedron. This definition is implicit and ensures uniqueness. Being situated "as far as possible" from the boundaries of the feasible value functions" polyhedron, the solution may also be considered as representative. There is however no guarantee that 
the selected value function perfectly represents DM's preferences. As already explained, the procedure enables the DM to either validate or reject the result. Note that the computation of the analytic center is not a linear problem. However, computations were performed using the Diviz software platform (Consortium Decision Deck, 2006-2010) and computation time remains reasonable in all of our experiments.

\subsection{Discussion}

Before presenting the SOQ model and applying the proposed procedure in an example, some general comments on the method can be made.

As already mentioned, several value functions are generally compatible with the preference information obtained from the DM. In the proposed interactive procedure, a specific one is chosen without any validation by the DM. We have indeed argued that this value function is only used to point out a possibly interesting solution. Instead of validating the preference model, the DM can either validate or reject the solution found by optimizing a specific value function. Another method is proposed by Stewart (1987) where the optimality of every alternative in $A$ is checked for every utility function compatible with the preference information obtained from the DM. If the optimality of an alternative is inconsistent in every case, this one is eliminated. In this method, a non eliminated alternative is randomly added to $A_{L}$ and the DM is asked to indicate preference information in relation with this new element. However, the work of Stewart (1987) is limited to the case where $A$ is finite. As it will be shown in the following models, operational decision problems are often characterized by an infinite decision space. Moreover, the interactive method of Stewart (1987) does not allow the DM to have evolving preferences. On the opposite, our procedure enables the DM to come back to the preference information given in Step 2.

It may also happen that the preference information obtained from the DM in Step 2 leads to an empty set of compatible value functions. In this case, two options can be considered. Either the DM can reduce the number of pairwise comparisons made by focusing on the ones he / she is more comfortable with. Doing so, the problem of finding a compatible value function will be less constrained. Or it can be concluded that the DM's preferences are not compatible with an additive value function model. The proposed algorithm is also compatible with non-additive value function models. For instance, Angilella et al. (2004) propose a preference disaggregation method for non-additive value functions.

In our procedure, the appropriateness of the result is deeply influenced by the selection of the learning set in Step 1. The learning set should not contain too many alternatives, and, on the other hand, it 
should be representative enough of the problem. The problem of selecting the most appropriate learning set may deserve future research. However, the proposed procedure can be easily modified to make the learning set denser in the region of the proposed solution $a^{*}$. Instead of presenting only one solution to the DM at each iteration, some solutions in the neighborhood of $a^{*}$ can also be proposed. We will nevertheless focus on the procedure proposed in Figure 1 in what follows.

The procedure can also take strict caps on some criteria into account. In this case, it can be assumed that the additive value function generated in Step 3 represents DM's preferences under reasonable limits. The learning set can be restricted to alternatives that respect the caps and the limitations can be added to the optimization problem in Step 4 by using constraints.

The next sections are devoted to the study of the SOQ model and to an extension of this model in the multi-echelon case.

\section{The sustainable order quantity model}

\subsection{Including SD criteria into the EOQ model}

The EOQ model was first developed by Harris (1913) even if Wilson (1934) is also recognized in connection with this model. Assuming a constant and continuous demand, a fixed leadtime and no shortage allowed, the average total cost per time unit has the following expression:

$C(Q)=P D+\frac{Q}{2} h+\frac{D}{Q} O$,

with:

$Q=$ batch quantity (decision variable),

$P=$ fixed purchase cost per product unit,

$D=$ demand per time unit,

$h=$ constant inventory holding cost per product unit and time unit,

$O=$ fixed ordering or setup cost.

As the cost function $C$ is strictly convex for $Q \in \mathfrak{R}_{+}^{*}$, the optimal batch quantity has the following expression:

$Q^{*}=\sqrt{\frac{2 O D}{h}}$.

It can be noticed that the value $P$ does not affect the optimal order quantity. This parameter will thus be omitted in what follows. 
Considering that minimizing the cost may not be the unique company objective, environmental and social objectives will be included into the model. We refer to this multiobjective extension of the EOQ model as the SOQ model. Determining the set of indicators that appropriately reflects the sustainable performances of operations is beyond the scope of this paper. Note that Bouchery et al. (2010) propose a methodology to build sustainable key performance indicators (KPIs) for distribution supply chains. A set of such KPIs for delivery and warehousing processes is also suggested.

From a general point of view, environmental and social impacts can be associated with both ordering and warehousing operations. A structure similar to Formula 2 is commonly used in the literature to quantify SD impacts (Benjaafar et al., 2010; Arslan and Turkay, 2010; Hua et al., 2011). Let $n$ be the number of criteria $\left(n \in \mathfrak{\aleph}^{*}\right)$. In this paper, each economic, environmental or social impact $C_{i}$ is thus evaluated by using the following formula:

$C_{i}(Q)=\frac{Q}{2} h_{i}+\frac{D}{Q} O_{i}, \forall i \in[1, n]$,

with:

$h_{i}, i \in[1, n]=$ constant inventory holding impact per product unit and time unit pertaining to criteria $i$ $O_{i}, i \in[1, n]=$ fixed ordering impact pertaining to criteria $i$.

In the decision space, the set of possible values for $Q$ is $A=\mathfrak{R}_{+}^{*}$. Let $C: A \rightarrow \mathfrak{R}^{n}$, $C(a)=\left\{C_{1}(a) ; \ldots ; C_{n}(a)\right\}, \quad \forall a \in A, \quad$ with $\quad C_{i} \quad$ defined by Formula $4, \quad \forall i \in[1, n]$. $A^{C}=C(A)=\left\{\left(C_{1}(Q), \ldots, C_{n}(Q)\right) \mid Q \in A\right\}$ is the image of $A$ in the criterion space (evaluation space). From a practical point of view, some alternatives of $A$ are out of interest for the DM as it exists other alternatives that have lower impacts in every criterion. We will analytically determine the efficient frontier $E$ of the SOQ model and derive some properties of its image $E^{C}=C(E)$ in the criterion space. We also introduce the following notations:

- $\mathfrak{R}_{+}^{n}=\left\{\left(x_{1}, \ldots, x_{n}\right) \mid x_{i} \in \mathfrak{R}_{+}, \forall i \in[1, n]\right\}$ is the nonnegative orthant of $\mathfrak{R}^{n}$,

- Let $S_{1}$ and $S_{2}$ two subsets of $\Re^{n}:\left(S_{1}+S_{2}\right)=\left\{S_{1}+s_{2} \mid s_{1} \in S_{1}, s_{2} \in S_{2}\right\}$ is the Minkowski sum, - $E_{+}^{C}=\left(E^{C}+\Re_{+}^{n}\right)$, see Figure 3 for a graphical example.

As $C_{i}(Q)$ is strictly convex for $Q \in \Re_{+}^{*}, \forall i \in[1, n]$, the single objective minimum is expressed as follows:

$Q_{i}^{*}=\sqrt{\frac{2 O_{i} D}{h_{i}}}$. 
We can assume without lack of generality that the criteria are arranged so that $Q_{1}^{*} \leq \ldots \leq Q_{n}^{*}$.

Theorem 1. Let $E$ be the efficient frontier of the SOQ problem and $E^{C}$ its image in the criterion space, then:

- $E=\left[Q_{1}^{*}, Q_{n}^{*}\right]$,

- $E_{+}^{C}$ is convex.

Proofs from here onwards are provided in Appendix A. Note that Theorem 1 is valid as soon as $C$ is a general strictly convex function. We propose to illustrate the results with two criteria $(n=2)$, for instance the cost and the carbon footprint. As an example, let $D=20$ product units per time unit, $O_{\cos t}=O_{1}=50, h_{\cos t}=h_{1}=1.5, O_{\text {emissions }}=O_{2}=200$ and $h_{\text {emissions }}=h_{2}=0.4$. It can be noticed that the parameters' units are omitted. Indeed, they are not useful as only the ratios $O_{i} / h_{i}$ matter. The parameters must nevertheless be expressed with the same unit within a criterion. Applying Formula (5), we get $Q_{1}^{*} \approx 37$ and $Q_{2}^{*} \approx 141$. Figure 2 illustrate the results.

Figure 2

Cost and carbon emissions in function of the batch size

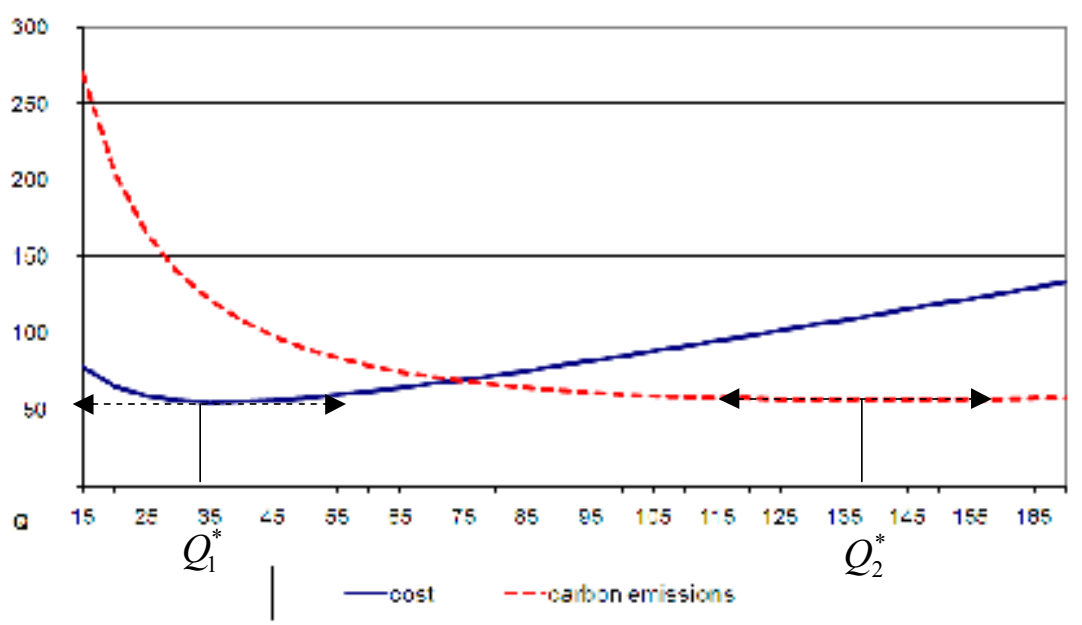

By applying Theorem 1, we obtain that $E=[37 ; 141]$. The image of the efficient frontier is illustrated in Figure 3. This example will be used to discuss the effectiveness of different regulatory policies to control carbon emissions.

First, it can be noticed that a significant carbon emissions reduction can be achieved by operational adjustment while requiring a reasonable financial effort. In this example, the carbon emissions can be reduced by $22 \%$ for a $5 \%$ cost increase starting from the minimal cost. This highlights that operational adjustments are effective to improve the sustainability of supply chains. On the contrary, the financial effort will increase as getting closer to the minimum amount of emissions. In this case, the firms will tend to invest in carbon-reducing technologies in addition to operational adjustments. 
Figure 3

The image of the efficient frontier in the criterion space

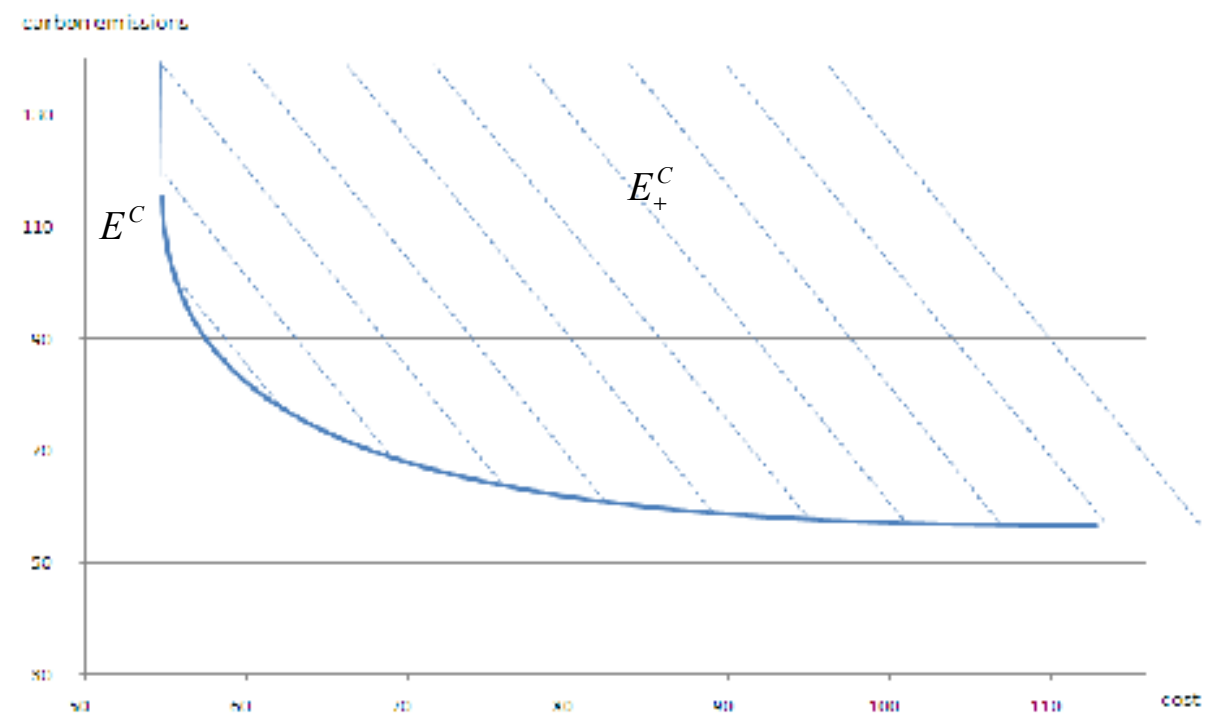

When focusing on regulatory policies, two decisions must be taken. First, policy makers should identify the most effective regulation policy. Second, companies have to react by optimizing their supply chains. Hua et al. (2011) and Benjaafar et al. (2010) have proven that emissions levels depend on the carbon price for the cap and trade system with a fixed carbon price. This is also the case for the carbon tax policy. For these two regulatory policies, the minimum amount of emissions cannot be achieved as it would imply an infinite carbon price.

Moreover, companies will have two possibilities to optimize their supply chains when facing a given carbon price. Companies can indeed make operational adjustments but they can also invest in carbonreducing technologies. The different options are not equivalent in terms of emissions. For a given carbon price, the amount of carbon emissions is thus quite unpredictable. It can then be concluded that the carbon tax policy and the cap and trade system are not very effective in controlling carbon emissions, even if establishing these regulatory policies enables reducing emissions. On the other hand, strict caps are more appropriate to control carbon emissions.

In the next section, a numerical example is given in order to illustrate the type of interaction and the type of result that the interactive procedure proposed in section 2.2 can produce for the SOQ model.

\subsection{Applying the proposed interative procedure to the SOQ model}

In this example, three criteria are taken into account for the SOQ model. We do not advocate that the proposed criteria are the most relevant ones but they are proposed as an example. As greenhouse gases reduction is nowadays a key issue, we decide to choose the carbon footprint as an environmental criterion. The fixed amount of carbon emissions per order represents the emissions related to order 
processing and transportation. An amount of carbon emissions can also be associated with the storage of each unit per time unit. The social dimension of SD has received less attention in the literature (White and Lee, 2009). There is a lack of consensus on how to assess the social performance of operations. In this example, we propose to use the injury rate as a social criterion. Injuries are indeed a major social impact of operations and are caused both by ordering and warehousing operations. For the numerical calculation, the chosen values are presented below.

Table 1

Example parameter's values

demand rate $(\mathrm{D})$

\begin{tabular}{ccccccc} 
ordering cost $\left(\mathrm{O}_{1}\right)$ & 100 & ordering carbon footprint $\left(\mathrm{O}_{2}\right)$ & 320 & ordering injury rate $\left(\mathrm{O}_{3}\right)$ & 119 \\
holding cost $\left(\mathrm{h}_{1}\right)$ & 1 & holding carbon footprint $\left(\mathrm{h}_{2}\right)$ & 0.45 & holding injury rate $\left(\mathrm{h}_{3}\right)$ & 0.27 \\
\hline
\end{tabular}

Applying Formula 5, the three single objective optima can be calculated (see Table 2).

Table 2

Single objective optima

\begin{tabular}{ccccc}
\hline & $Q_{i}^{*}$ & Cost $C_{1}$ & Carbon Emissions $C_{2}$ & Injuries $C_{3}$ \\
\hline economic order quantity & 71 & 70.7 & 128.7 & 51.5 \\
social order quantity & 148 & 90.9 & 87.4 & 40.1 \\
environmental order quantity & 189 & 107.7 & 84.9 & 41.3 \\
\hline
\end{tabular}

Applying Theorem 1, the efficient frontier consists of any batch sizes between [71; 189]. The range on each criterion also appears in Table 2. The final solution will depend on the relative importance the DM gives to each of the three criteria. For this didactic example, we will imagine an interaction with a fictitious DM so as to illustrate the type of interaction and the type of result that the proposed method can produce. Only the images of the alternatives in the criterion space are presented to the DM.

\section{Iteration 1:}

Step 1: We decide to include the three single objective optima ( $a_{1}, a_{3}$ and $a_{5}$ respectively) as well as two other solutions into the learning set (see Table 3).

Table 3

The initial learning set

\begin{tabular}{cccc}
\hline & Cost $C_{1}$ & Carbon emissions $C_{2}$ & Injuries $C_{3}$ \\
\hline $\mathrm{a}_{1}$ & 70.7 & 128.7 & 51.5 \\
$\mathrm{a}_{2}$ & 77.7 & 97.5 & 41.9 \\
$\mathrm{a}_{3}$ & 90.9 & 87.4 & 40.1 \\
$\mathrm{a}_{4}$ & 99.3 & 85.4 & 40.4 \\
$\mathrm{a}_{5}$ & 107.7 & 84.9 & 41.3 \\
\hline
\end{tabular}

Step 2: Assume that the DM provides the following preference information: $a_{2} \mathrm{f} a_{4} \mathrm{f} a_{1}$ ( $f$ corresponds to strict preference). 
Step 3: ACUTA is used with the provided preference information to compute a compatible value function:

$V(Q)=\sum_{i=1}^{3} v_{i}\left(C_{i}(Q)\right)$

Step 4: $V(Q)$ can then be maximized. The optimum is found for $Q=120$, the corresponding alternative is $a_{6}(80.8 ; 93.7 ; 41.0)$.

Step 5: The DM may consider that $a_{6}$ is not satisfactory, this one is added to $A_{L}$.

\section{Iteration 2:}

Step 2: The DM may provide the following additional information: $a_{2} f a_{6} f a_{4} f a_{1}$.

Steps 3 and 4: With this new information, a new value function can be generated and optimized. The optimum is found for $Q=102$, the corresponding alternative is $a_{7}(75.5 ; 101.4 ; 42.9)$.

Step 5: The DM may consider that $a_{7}$ is not satisfactory, this one is added to $A_{L}$.

\section{Iteration 3:}

Step 2: The following preference information may be given by the DM: $a_{2} \mathrm{f} a_{7} \mathrm{f} a_{6} \mathrm{ft} a_{4} \mathrm{f} a_{1}$.

Step 3 and 4: The optimum of the new value function is found for $Q=109$, the corresponding alternative is $a_{8}(77.4 ; 98.0 ; 42.0)$.

Step 5: Assume that the solution $a_{8}$ is satisfactory for the DM, the procedure stops.

It can be noticed that the resulting solution is relatively close to alternative $a_{2}$ which was randomly generated in Step 1. However, the DM feels more confident with alternative $a_{8}$ as he / she has learnt about the problem and about his / her own preferences. The proposed procedure enables an effective interaction with the DM as a satisfactory solution is quickly identified.

The next section is devoted to the sensitivity analysis of the results.

\subsection{Sensitivity analysis}

The previous section has shown that the proposed interactive procedure allows the DM to quickly find a satisfactory solution for the SOQ model. However, this procedure will be used in practice only if it ensures a certain kind of robustness. The following result proves that the procedure is quite insensitive to a slightly change or an estimation error for any parameter of the model. 
Recall that in the SOQ model, $n$ criteria $\left(n \in \mathcal{N}^{*}\right)$ are evaluated by using Formula 4, $C_{i}(Q)=\frac{Q}{2} h_{i}+\frac{D}{Q} O_{i}, \forall i \in[1, n]$. Assume that the value function generated in the last iteration of the proposed interactive procedure represents DM's preferences. This value function is noted $V^{*}(Q)=\sum_{i=1}^{n} v_{i}^{*}\left(C_{i}(Q)\right)$ and is maximal for $Q=Q^{*}$. By using ACUTA, $\forall i \in[1, n], v_{i}^{*}$ is piecewise linear decreasing. The following theorem proves that $V^{*}$ behaves as a cost function $C_{e q}(Q)=\frac{Q}{2} h_{e q}+\frac{D}{Q} O_{e q}$ in a neighborhood of $Q^{*}$, with $h_{e q}=\sum_{i=1}^{n} \alpha_{i} h_{i}$ and $O_{e q}=\sum_{i=1}^{n} \alpha_{i} O_{i}$. It implies that $V^{*}$ has the same robustness as the cost function in the EOQ model.

Theorem 2. There exists $Q_{\min }<Q_{\max } \in \mathfrak{R}_{+}^{*}$ such that:

$$
\begin{aligned}
& -Q^{*} \in\left[Q_{\min }, Q_{\max }\right], \\
& \text { - } \forall Q \in\left[Q_{\min }, Q_{\max }\right], V^{*}\left(Q^{*}\right)-V^{*}(Q)=C_{e q}(Q)-C_{e q}\left(Q^{*}\right) .
\end{aligned}
$$

The coefficients $\alpha_{i}$ can be obtained by using the following formula for $Q \in\left[Q_{\min }, Q_{\max }\right]$ such that $Q \neq Q^{*}:$

$\alpha_{i}=\frac{v_{i}^{*}\left(C_{i}(Q)-C_{i}\left(Q^{*}\right)\right)}{C_{i}(Q)-C_{i}\left(Q^{*}\right)}$.

For $Q \notin\left[Q_{\min }, Q_{\max }\right]$, a deviation appears between $V^{*}\left(Q^{*}\right)-V^{*}(Q)$ and $C_{e q}(Q)-C_{e q}\left(Q^{*}\right)$. Figure 4 illustrates Theorem 2, the chosen value function is the one obtained in iteration 3 of section 3.2.

Figure 4

Illustration of Theorem 2

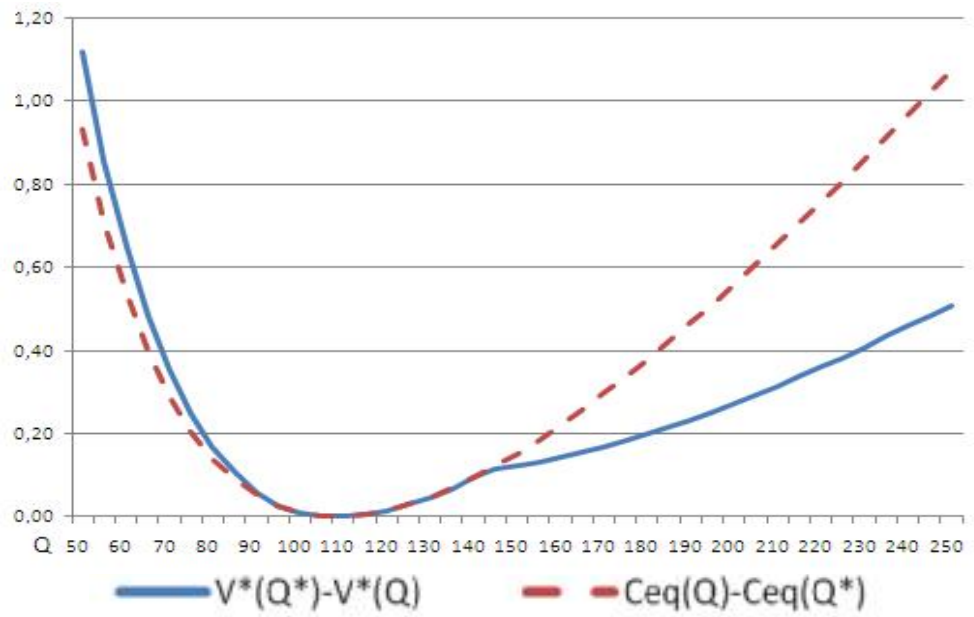

For this example, recall that $Q^{*}=109 . V^{*}$ behaves like an a cost function in the EOQ model for a wide range of values as the segment $\left[Q_{\min }, Q_{\max }\right]$ is equal to $[95,140]$. Note that Theorem 2 also 
implies that $V^{*}$ can be considered as a weighted sum of the criteria in the neighborhood of $Q^{*}$. In this case, the coefficients $\alpha_{i}$ may represent the weights.

\section{The two-echelon serial sustainable order quantity model}

\subsection{Problem presentation and preliminary results}

In this section, an extension of the EOQ model in a multi-echelon case is presented. The considered model is a serial system with 2 echelons, where one warehouse supplies a single retailer (see Figure 5). The model was first studied by Schwarz (1973).

Figure 5

The two-echelon serial system

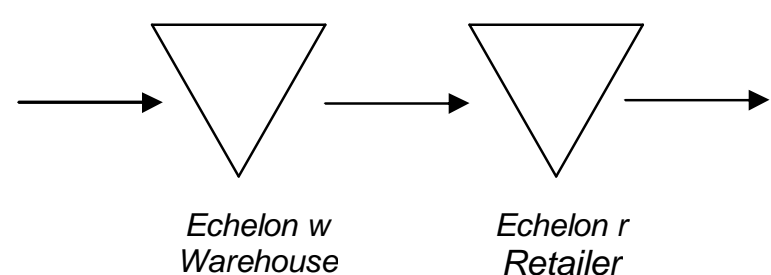

The retailer faces a constant continuous demand. Leadtimes are assumed to be zero for clarity reason (fixed leadtimes can be easily handled) and no shortage is allowed. Moreover, initial inventories are assumed to be zero. Fixed ordering costs and linear holding costs are supported at each location. Let $Q_{r}$ and $Q_{w}$ be the batch quantities ordered by the retailer and by the warehouse respectively. The entire batch is delivered at the same time. The following result is issued from Schwarz (1973).

$\begin{aligned} \text { Preliminary Result. } & \text { An optimal policy is stationary-nested and respects the zero-inventory } \\ & \text { condition i.e.: } \\ & -Q_{r} \text { and } Q_{w} \text { are time invariant, } \\ & -Q_{w}=k \cdot Q_{r}, \text { with } k \in \aleph^{*}, \\ & - \text { The retailer orders only if its inventory level is null, } \\ & \text { - The warehouse orders when both the retailer and the warehouse have no } \\ & \text { inventory. }\end{aligned}$

To simplify the notations, let $Q_{r}=Q$. The total cost can then be expressed in function of $Q$ and $k$ :

$C(k, Q)=\left(h_{r}+(k-1) h_{w}\right) \frac{Q}{2}+\left(O_{r}+\frac{O_{w}}{k}\right) \frac{D}{Q}$,

with:

$Q=$ batch quantity at the retailer (first decision variable), 
$k=$ strictly positive integer such that $Q_{w}=k \cdot Q$ (second decision variable),

$D=$ demand per time unit,

$h_{r}=$ constant inventory holding cost per product unit and time unit at the retailer,

$h_{w}=$ constant inventory holding cost per product unit and time unit at the warehouse,

$O_{r}=$ fixed ordering cost at the retailer,

$O_{w}=$ fixed ordering cost at the warehouse.

If $h_{r}<h_{w}$, the minimum of Formula 8 is found for $k^{*}=1$. Else, let $k^{\mathrm{inf}}=\sqrt{\frac{O_{w}\left(h_{r}-h_{w}\right)}{O_{r} h_{w}}} \cdot k^{*}$ is a strictly positive integer that can be found by using the following rule. If $k^{\text {inf }}<1$, it is optimal to choose $k^{*}=1$. Else, let $k^{\prime} \leq k^{\text {inf }} \leq k^{\prime}+1$ with $k^{\prime} \in \mathfrak{\aleph}^{*}$. If $\frac{k^{\text {inf }}}{k^{\prime}} \leq \frac{k^{\prime}+1}{k^{\text {inf }}}$ then it is optimal to choose $k^{*}=k^{\prime}$.

Otherwise, $k^{*}=k^{\prime}+1$ (Axsäter, 2006). It follows that,

$Q^{*}=\sqrt{\frac{2 D\left(O_{r}+\frac{O_{w}}{k^{*}}\right)}{h_{r}+\left(k^{*}-1\right) h_{w}}}$.

We will now consider the case where several criteria $(n \geq 2)$ have to be taken into account and we refer to this problem as the two-echelon serial SOQ problem. Theorem 3 proves that each efficient ordering policy (efficient solution) can be found in the set of "basic" policies.

Theorem 3. For the two-echelon serial SOQ problem, an ordering policy leading to an efficient solution is basic i.e.:

- The retailer orders only if its inventory level is null,

- The warehouse orders when both the retailer and the warehouse have no inventory.

- All deliveries made to the retailer between successive deliveries to the warehouse are of equal size.

In what follows, we will restrict our attention to stationary policies as non-stationary ones are often too complicated to be implemented in practice. Note that the following results can be extended if nonstationary policies are of interest for the DM. Focusing on stationary policies, preliminary results holds and the simplified notations $Q$ and $k$ are kept. Each SD impact $C_{i}$ is thus evaluated by using the following formula:

$C_{i}(k, Q)=\left(h_{i r}+(k-1) h_{i w}\right) \frac{Q}{2}+\left(O_{i r}+\frac{O_{i w}}{k}\right) \frac{D}{Q}, \forall i \in[1, n]$,

with:

- $h_{i r}, i \in[1, n]:$ constant inventory holding impact $i$ per product unit and time unit at the retailer, 
- $h_{i w}, i \in[1, n]$ : constant inventory holding impact $i$ per product unit and time unit at the warehouse,

- $O_{i r}, i \in[1, n]$ : ordering impact $i$ per order at the retailer,

- $O_{i w}, i \in[1, n]$ : ordering impact $i$ per order at the warehouse.

$\forall i \in[1, n]$, if $h_{i r}<h_{i w}, k_{i}^{*}=1$.Else, $k_{i}^{*}$ is a strictly positive integer that can be found by using the rule described earlier with $k_{i}^{\text {inf }}=\sqrt{\frac{O_{i w}\left(h_{i r}-h_{i w}\right)}{O_{i r} h_{i w}}}, \forall i \in[1, n]$. The minimum of Formula 10 is found for:

$Q_{i}^{*}=\sqrt{\frac{2 D\left(O_{i r}+\frac{O_{i w}}{k_{i}^{*}}\right)}{h_{i r}+\left(k_{i}^{*}-1\right) h_{i w}}}$, and $k_{i}^{*}$ defined above, $\forall i \in[1, n]$.

The next section is devoted to the identification of the efficient frontier of the two-echelon serial SOQ problem.

\subsection{Multiobjective optimization of the two-echelon serial SOQ model}

In this section, some theorems that allow characterizing the efficient frontier of the two-echelon serial SOQ problem are presented. Comparing to the mono-echelon SOQ model, a strictly positive integer $k$ is added as decision variable. Let $n$ be the number of criteria $\left(n \in \mathfrak{N}^{*}\right)$. In the decision space, the set of possible alternatives $A$ is $\left\{(k, Q) \mid k \in \mathfrak{N}^{*}, Q \in \mathfrak{R}_{+}^{*}\right\}$. Let $C: A \rightarrow \mathfrak{R}^{n}, C(a)=\left\{C_{1}(a) ; \ldots ; C_{n}(a)\right\}, \forall a \in A$, with $C_{i}$ defined by Formula 10, $\forall i \in[1, n]$. The image of $A$ in the criterion space is $A^{C}=\left\{\left(C_{1}(k, Q), \ldots, C_{n}(k, Q)\right) \mid(k, Q) \in A\right\}$. Let $E$ be the efficient frontier of the problem and $E^{C}=C(E)$ its image in the criterion space. Moreover, let $E_{+}^{C}=\left(E^{C}+\Re_{+}^{n}\right)$.

We will first consider the case with $k$ fixed. $A_{k}^{C}=\left\{\left(C_{1}(k, Q), \ldots, C_{n}(k, Q)\right) \mid Q \in \mathfrak{R}_{+}^{*}\right\}, \forall k \in \mathfrak{N}^{*}$. The efficient frontier of this sub-problem is noted $E_{k}$ and $E_{k}^{C}$ is its image in the criterion space. Let $E_{k+}^{C}=\left(E_{k}^{C}+\Re_{+}^{n}\right)$. As Formula 11 is strictly convex in $Q$, assume that $Q_{i}^{k^{*}}$ minimizes $C_{i}(k, Q)$.

Theorem 4. Let $E_{k}$ be the efficient frontier of the two-echelon serial SOQ with $k$ fixed and $E_{k}^{C}$ its image in the criterion space, then:

- $E_{k}=\left[\min _{i}\left(Q_{i}^{k^{*}}\right), \max _{i}\left(Q_{i}^{k^{*}}\right)\right]$,

- $E_{k+}^{C}$ is convex. 
It can be noticed that $E^{C} \subset \bigcup_{k=1}^{\infty} E_{k}^{C}$. We could intuitively expect that $E^{C} \subset \bigcup_{k=\min \left(k_{i}^{*}\right)}^{\max \left(k_{i}^{*}\right)} E_{k}^{C}$. However, a counterexample can be found even for $n=2$ (Table 4). Applying Formula 11 to the example presented in Table 4 , we get $k_{1}^{*}=3$ and $k_{2}^{*}=3$. It could then be tempting to conclude that $E^{C}=E_{3}^{C}$. However, some elements of $E_{4}^{C}$ are also efficient. This can be seen in Figure 6. In this example, $E^{C} \subset\left\{E_{3}^{C} \cup E_{4}^{C}\right\}$.

Table 4

Example data set

demand rate $(\mathrm{D})$

holding impact 1 at the retailer $\left(\mathrm{h}_{1 \mathrm{r}}\right)$

holding impact 1 at the warehouse $\left(\mathrm{h}_{1 \mathrm{w}}\right)$

ordering impact 1 at the retailer $\left(\mathrm{O}_{1 \mathrm{r}}\right)$

ordering impact 1 at the warehouse $\left(\mathrm{O}_{1 \mathrm{w}}\right)$
50

10

6

50

500 holding impact 2 at the retailer $\left(\mathrm{h}_{2 \mathrm{r}}\right)$

holding impact 2 at the warehouse $\left(\mathrm{h}_{2 \mathrm{w}}\right) \quad 0.5$

ordering impact 2 at the retailer $\left(\mathrm{O}_{2 \mathrm{r}}\right) \quad 10$

ordering impact 2 at the warehouse $\left(\mathrm{O}_{2 \mathrm{w}}\right) \quad 10$

Figure 6

The example criterion space

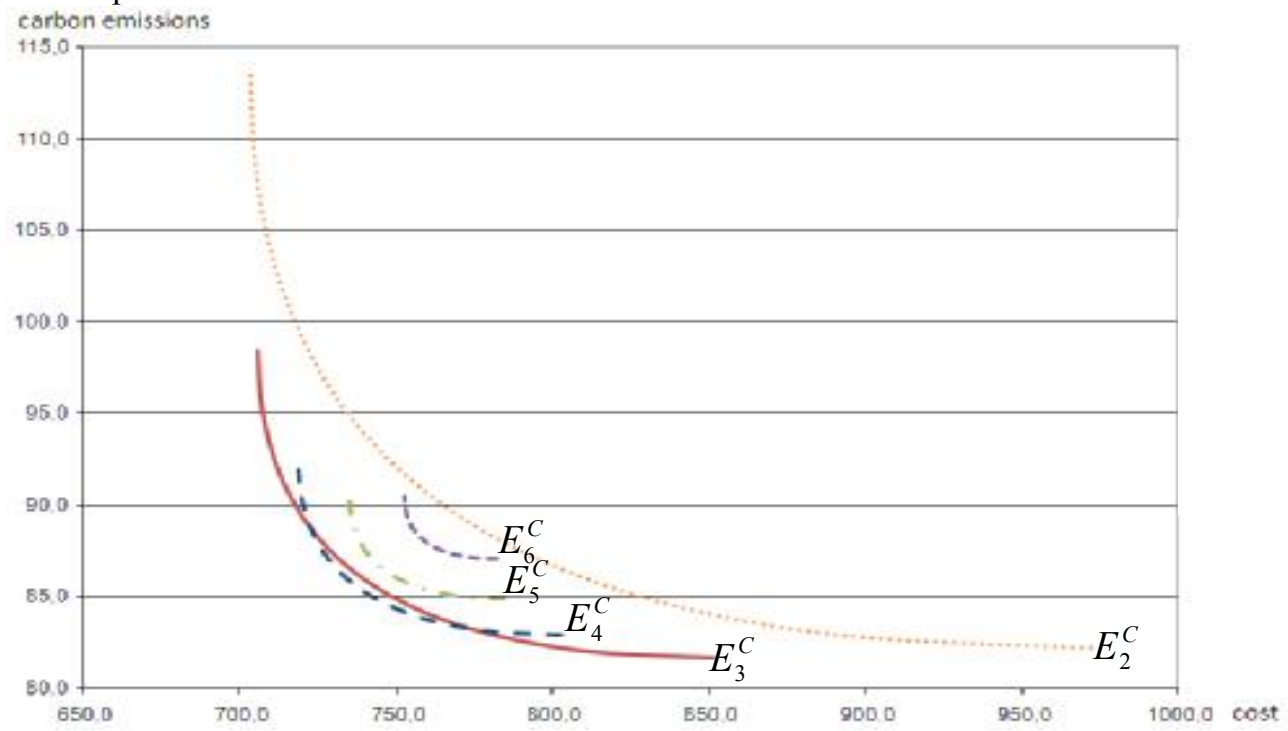

Theorem 5 states that a lower bound $k_{\min }$ and an upper bound $k_{\max }$ exist such that $E^{C} \subset \bigcup_{k=k_{\min }}^{k_{\max }} E_{k}^{C}$.

Theorem 5. There exists $\left(k_{\min }, k_{\max }\right) \in \boldsymbol{\aleph}^{* 2}$ such that:

$$
\begin{aligned}
& -1 \leq k_{\min } \leq \min _{i}\left(k_{i}^{*}\right), \\
& -\max _{i}\left(k_{i}^{*}\right) \leq k_{\max }, \\
& E^{C} \subset \bigcup_{k=k_{\min }}^{k_{\max }} E_{k}^{C} .
\end{aligned}
$$

It can also be noticed in the above example that $E_{+}^{C}$ is non convex. This result can be generalized as soon as $E^{C}$ is not included into a single set $E_{k}^{C}$. This condition necessarily holds when 
$\min _{i}\left(k_{i}^{*}\right) \neq \max _{i}\left(k_{i}^{*}\right)$. However, the example above proves that the reciprocal is not true. This result is stated in Theorem 6 .

Theorem 6. If $\min _{i}\left(k_{i}^{*}\right)<\max _{i}\left(k_{i}^{*}\right)$, then $E_{+}^{C}$ is non convex.

An illustration of the two-echelon serial SOQ problem is given with two criteria (the cost and the carbon footprint). Parameter's value can be found in Table 5.

Table 5

Example data set

demand rate $(\mathrm{D})$

holding impact 1 at the retailer $\left(\mathrm{h}_{1 \mathrm{r}}\right)$

holding impact 1 at the warehouse $\left(\mathrm{h}_{1 \mathrm{w}}\right)$

ordering impact 1 at the retailer $\left(\mathrm{O}_{1 \mathrm{r}}\right)$

ordering impact 1 at the warehouse $\left(\mathrm{O}_{1 \mathrm{w}}\right)$

\section{0}

8

4

80

350 holding impact 2 at the retailer $\left(\mathrm{h}_{2 \mathrm{r}}\right)$

2

holding impact 2 at the warehouse $\left(\mathrm{h}_{2 \mathrm{w}}\right)$

0.15

ordering impact 2 at the retailer $\left(\mathrm{O}_{2 \mathrm{r}}\right)$

45

ordering impact 2 at the warehouse $\left(\mathrm{O}_{2 \mathrm{w}}\right)$

It can be noticed that $E_{+}^{C}$ is non convex in this example (See Figure 7). In this case, some efficient solutions cannot be generated by using a linear combination of the objectives. For instance, $E_{2}^{C} \cap E_{3}^{C}$ is an efficient solution that cannot be found by optimizing a linear combination of the two objectives. However, this solution can represent a desirable compromise for the company. The interactive procedure described in section 2.2 enables proposing such solutions by optimizing an additive value function instead of a simple weighted sum. This strengthens the proposed interactive procedure.

Figure 7

The image of the efficient frontier in the criterion space

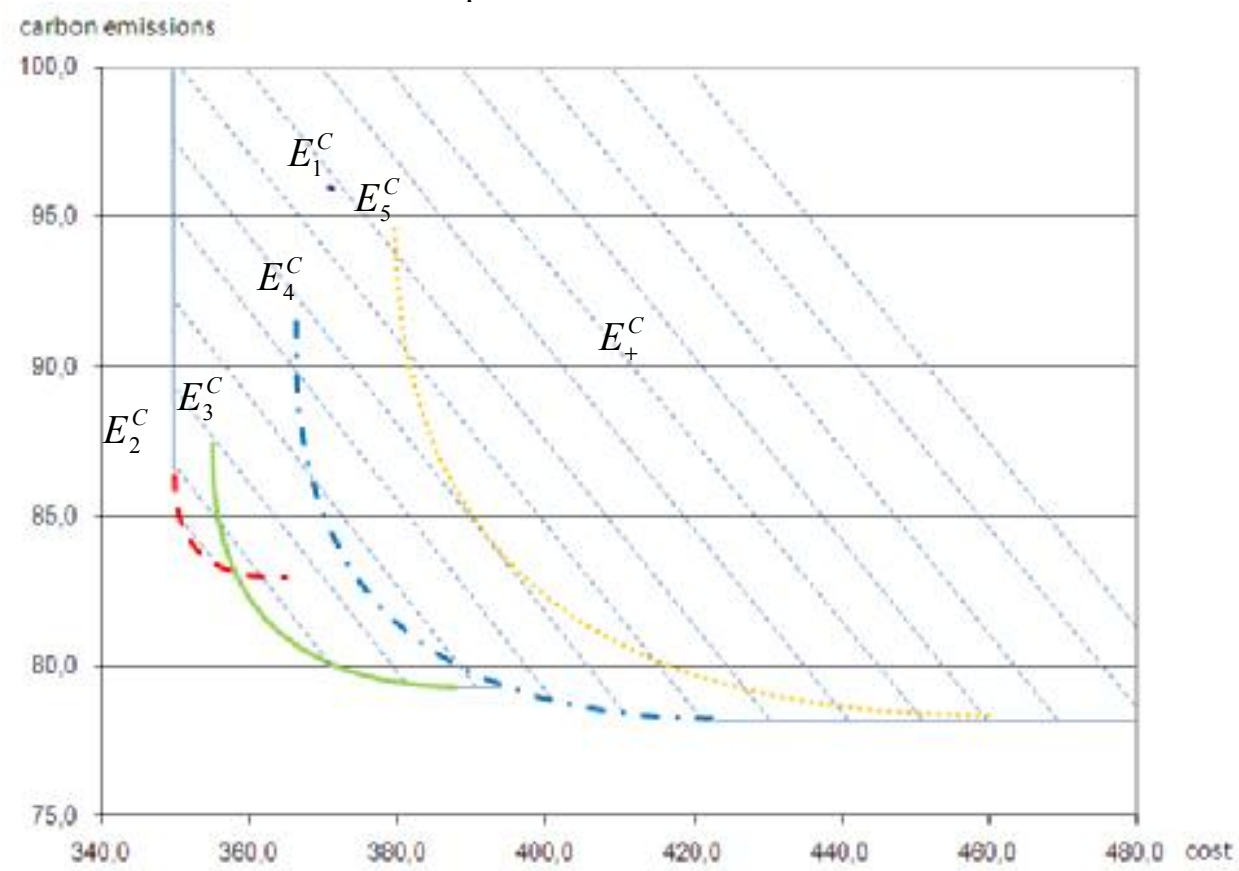


The same interpretation can be done when focusing on the carbon tax. As a traditional carbon tax scheme is a linear one, some operational efficient solutions are ruled out. This problem could be overcome by using non linear tax schemes. The proposed interactive procedure could be used in this case to find a non linear carbon tax function that seems satisfactory for policy makers. The marginal value functions $v_{i}$ can be interpreted as the tax function and could thus be presented to policy makers.

\section{Conclusion}

This paper presents a novel approach for integrating SD criteria into inventory model. In order to consider the different aspects of sustainability, we propose to formulate inventory models as multiobjective problems. We thus consider a multiobjective formulation of the EOQ model called the SOQ model. A multi-echelon extension of the SOQ model is also studied. For both models, the efficient frontier is analytically characterized and the results are used to analyze the effectiveness of different regulatory policies to control carbon emissions. We also propose an interactive procedure that allows the decision maker to quickly identify his / her best option among these solutions.

Further research directions are numerous. First of all, other inventory models could be revisited. The study of more complex models could nevertheless be difficult as optimal solutions are often hard to determine even in the mono-objective case (see e.g. Crowston et al. (1973); Roundy (1985) or Roundy (1986)). In this case, closed to optimal solutions could be used. Other OM decisions could also be revisited by considering the problem as multiobjective. For instance, facilities location, supplier selection and transportation mode selection also affect the sustainability of the supply chain.

An interesting question arises when the DM has to explain his / her choice. The additive value functions selected in the proposed procedure can of course be used to explain the decision. Another interesting research direction could consist in adapting the dominance-based rough set approach proposed in Greco et al. (2008b). In this case, the DM could select a rule that is concordant with the given preference information. This rule could then be added to the model and a new learning set could be generated. This approach could simplify the explanation of the decision.

Finally, operational decisions usually involve more than one DM within a company and more than one company along the supply chain. Research aiming at including SD criteria into inventory models with multiple actors should be conducted. For instance, investigating the impact of collaboration among companies with SD concerns is of major interest. The way to handle the multiplicity of the DMs within a company should also be studied. 


\section{Appendix A}

\section{Proof of Theorem 1:}

Identification of the efficient frontier:

If $Q_{1}^{*}=Q_{n}^{*}, E=Q_{1}^{*}$ as $C_{i}\left(Q_{1}^{*}\right)$ is the unique minimum on each criteria $i$.

Assume that $Q_{1}^{*}<Q_{n}^{*}$ :

- $C_{1}(Q)$ is strictly increasing on $\left[Q_{1}^{*}, Q_{n}^{*}\right]$,

- $C_{n}(Q)$ is strictly decreasing on $\left[Q_{1}^{*}, Q_{n}^{*}\right]$,

- $\forall i \in[1, n], C_{i}(Q)$ is strictly increasing on $\left[Q_{n}^{*}, \infty\right)$ and strictly decreasing on $\left(0, Q_{1}^{*}\right]$ then the solution is dominated if $Q \notin\left[Q_{1}^{*}, Q_{n}^{*}\right]$,

then $E=\left[Q_{1}^{*}, Q_{n}^{*}\right]$.

\section{Convexity:}

As $\Re_{+}^{n}$ is convex, we only have to prove that $\forall(a, b) \in E^{C} \times E^{C}$, the segment $[a, b]$ is included into $E_{+}^{C}$.

Let $(a, b) \in E^{C} \times E^{C}$, if $a=b, a \in E_{+}^{C}$ by definition.

Else, let $a=C\left(Q_{a}\right)$ and $b=C\left(Q_{b}\right)$ with $\left(Q_{a}, Q_{b}\right) \in\left[Q_{1}^{*}, Q_{n}^{*}\right] \times\left[Q_{1}^{*}, Q_{n}^{*}\right]$.

$a \in E_{+}^{C}$ and $b \in E_{+}^{C}$.

$\forall \lambda \in] 0,1\left[\right.$, let $x_{\lambda}=\lambda \cdot a+(1-\lambda) \cdot b$.

As $C$ is strictly convex, $x_{\lambda}$ is dominated by $C\left(\lambda \cdot Q_{a}+(1-\lambda) \cdot Q_{b}\right)$.

So, $x_{\lambda} \in E_{+}^{C}$.

\section{Proof of Theorem 2:}

$v_{i}^{*}$ are piecewise linear decreasing then it exits $\left(Q_{\min }, Q_{\max }\right) \in \mathfrak{R}_{+}^{*} \times \mathfrak{R}_{+}^{*}$ such that:

- $Q^{*} \in\left[Q_{\min }, Q_{\max }\right]$,

- $\forall i \in[1, n]$, it exists $\alpha_{i} \in \mathfrak{R}_{+}^{*} \mid \forall Q \in\left[Q_{\min }, Q_{\max }\right], v_{i} *\left(C_{i}(Q)\right)=v_{i}\left(C_{i}\left(Q^{*}\right)\right)-\alpha_{i}\left(C_{i}(Q)-C_{i}\left(Q^{*}\right)\right)$.

By applying Formula (6), we obtain that $\forall Q \in\left[Q_{\min }, Q_{\max }\right]$ :

$V^{*}(Q)=\sum_{i=1}^{n} v_{i}^{*}\left(C_{i}(Q)\right)=V^{*}\left(Q^{*}\right)+\left(\frac{h_{e q} \cdot Q^{*}}{2}+\frac{O_{e q} \cdot D}{Q^{*}}\right)-\left(\frac{h_{e q} \cdot Q}{2}+\frac{O_{e q} \cdot D}{Q}\right)$, with $h_{e q}=\sum_{i=1}^{n} \alpha_{i} \cdot h_{i}$ and $O_{e q}=\sum_{i=1}^{n} \alpha_{i} \cdot O_{i}$.

It follows that:

$\forall Q \in\left[Q_{\min }, Q_{\max }\right], V^{*}\left(Q^{*}\right)-V^{*}(Q)=C_{e q}(Q)-C_{e q}\left(Q^{*}\right)$.

\section{Proof of Theorem 3: Similar to that of Schwartz (1973)}

(1) The retailer orders only if its inventory level is null:

Consider any feasible policy that does not satisfy (1) at some time t. Every holding impacts in the interval $[0, t]$ will be reduced by reducing the amount of the preceding delivery by the inventory on hand at time $t$ (or to zero) and increasing the amount of the delivery at time $t$ by the same amount. This 
adjustment does not increase the number of deliveries and ordering impacts are thus reduced or kept equal. By repeating this adjustment for every retailer delivery time, a policy satisfying (1) will result.

(2) The warehouse orders when both the retailer and the warehouse have no inventory:

The fact that the warehouse orders when its inventory level is null is proven in the same manner as (1). To prove that the warehouse orders when the retailer has no inventory, we remark that on the other case, the warehouse order can be postponed until the retailer orders. This will decrease every holding impact at the warehouse without modifying the ordering impacts. By applying (1), this condition happens when the inventory at the retailer is null.

(3) All deliveries made to the retailer between successive deliveries to the warehouse are of equal size:

Assume that there are ${ }_{n}$ deliveries to the retailer of lot sizes $Q_{k}, k \in[1, n]$ such that $\sum_{k=1}^{n} Q_{k}=Q$ between any two successive deliveries to the warehouse. The only impacts affected by these lot sizes are the holding impacts at the retailer. As $D$ is constant, the minimum of all holding impacts at the retailer is reached when $\forall k \in[1, n], Q_{k}=\frac{Q}{n}$.

\section{Proof of Theorem 4:}

Similar to that of Theorem 1.

\section{Proof of Theorem 5:}

The existence of $k_{\min }$ is trivial.

Moreover, the mono-objective optima defined in Formula 11 are included in $E$ by definition, then $1 \leq k_{\min } \leq \min _{i}\left(k_{i}^{*}\right)$.

It also implies that if $k_{\max }$ exists, $\max _{i}\left(k_{i}^{*}\right) \leq k_{\max }$.

$\forall i \in[1, n], C_{i}(k, Q)$ tends to infinity as $k$ tends to infinity. Let $e\left(k_{e}, Q_{e}\right) \in E$.

It exits $t \in \mathfrak{\aleph}^{*}$ such that $\forall i \in[1, n], \forall Q \in \mathfrak{R}_{+}^{*}, \forall n \in \mathfrak{\aleph}, C_{i}\left(k_{e}, Q_{e}\right)<C_{i}(t+n, Q)$.

Then $e$ dominates all elements of $\bigcup_{k=t}^{\infty} E_{k}$. That proves the existence of $k_{\max }$.

\section{Proof of Theorem 6:}

By using Theorem 5, $E^{C} \subset \bigcup_{k=k_{\min }}^{k_{\max }} E_{k}^{C}$.

As $\min _{i}\left(k_{i}^{*}\right)<\max _{i}\left(k_{i}^{*}\right)$, there exists $e_{k_{\min }} \in E_{k_{\min }}^{C} \mid e_{k_{\min }} \in E^{C}$ and $e_{k_{\max }} \in E_{k_{\max }}^{C} \mid e_{k_{\max }} \in E^{C}$.

$E_{\min \left(k_{i}^{*}\right)+}^{C} \neq E_{\max _{i}\left(k_{i}^{*}\right)+}^{C}$ and both are convex by using Theorem 4 thus $E^{C}$ is non convex. 


\section{References}

Angilella, S., Greco, S., Lamantia, F., Matarazzo, B., 2004. Assessing non-additive utility for multicriteria decision aid. European Journal of Operational Research, 158(3), 734-744.

Arslan, M.C., Turkay M., 2010. EOQ Revisited with Sustainability Considerations, working paper.

Axsäter, S., 2006. Inventory control, Springer, New York.

BearingPoint, 4th Supply Chain Monitor, 2010-2011, Available at http://www.bearingpointconsulting.com/de-de/download/TAP-SC EN.pdf, accessed on June $17,2011$.

Benjaafar, S., Li, Y., Daskin, M., 2010. Carbon Footprint and the Management of Supply Chains: Insights from Simple Models, working paper.

Beuthe, M., Scannella, G., 1996. Applications comparées des méthodes d'analyse multicritère UTA. RAIRO Operations Research, 30, 293-315.

Beuthe, M., Scannella, G., 2001. Comparative analysis of UTA multicriteria methods. European Journal of Operational Research, 130, 246-262.

Blengini, G.A., Shields, D.J., 2010. Green Labels and Sustainability Reporting. Management of Environmental Quality: An International Journal, 21(4), 477-493.

Bonney, M., Jaber, M.Y., 2011. Environmentally responsible inventory models: Non-classical models for a non-classical era. International Journal of Production Economics, 133(1), 43-53.

Bouchery, Y., Ghaffari, A., Jemai, Z., 2010. Key Performance Indicators for Sustainable Distribution Supply Chains: Set Building Methodology and Application. Cahiers de recherche 2010-08, Laboratoire Génie Industriel, Ecole Centrale Paris.

Bous, G., Fortemps, P., Glineur, F., Pirlot, M., 2010. ACUTA: A novel method for eliciting additive value functions on the basis of holistic preference statements. European Journal of Operational Research, 206(2), 435-444.

Carter C., Rogers D.S., 2008. A framework of sustainable supply chain management: moving toward new theory. International Journal of Physical Distribution \& Logistics Management, 38(5), $360-387$.

Consortium Decision Deck., 2006-2010. Decision deck: an open-source software platform for mcda methods. Www.decision-deck.org.

Crowston, W.B., Wagner, M., Williams, J.F., 1973. Economic Lot Size Determination in MultiStage Assembly Systems. Management Science, 19(5), 517-527.

Figueira, J.R., Greco, S., Mousseau, V., Slowinski, R., 2008b. Interactive Multiobjective Optimization Using a Set of Additive Value Functions. In: Branke, J. et al., (Eds.): Multiobjective Optimization, Springer, Heidelberg. 
Figueira, J.R., Greco, S., Slowinski, R., 2009. Building a set of additive value functions representing a reference preorder and intensities of preference: GRIP method. European Journal of Operational Research, 195(2), 460-486.

Figueira, J., Greco, S., Slowinski, R.,, 2008a. Identifying the "most representative" value function among all compatible value functions in the GRIP method. In: Communication at the 68th Meeting of the EURO Working Group "Multiple Criteria Decision Aiding”, Chania, Crete, October 2-3.

Greco, S., Matarazzo, B., Słowiński, R., 2008b. Dominance-Based Rough Set Approach to Interactive Multiobjective Optimization. In J. Branke et al., eds. Multiobjective Optimization. Springer Berlin Heidelberg, 121-155.

Greco, S., Mousseau, V., Slowinski, R., 2008a. Ordinal regression revisited: Multiple criteria ranking using a set of additive value functions. European Journal of Operational Research, 191(2), 416-436.

Harris, F.W., 1913. How Many Parts to Make at Once, factory, The Magazine of Management, 10, 135-136, 152.

Hua, G., Cheng, T.C.E., Wang, S., 2011. Managing carbon footprints in inventory management. International Journal of Production Economics, 132(2), 178-185.

Jacquet-Lagrèze, E., Meziani, R., Slowinski, R., 1987. MOLP with an interactive assessment of a piecewise-linear utility function. European Journal of Operational Research, 31(3), 350-357.

Jacquet-Lagreze, E., Siskos, Y., 1982. Assessing a set of additive utility functions for multicriteria decision-making, the UTA method. European Journal of Operational Research, 10(2), 151164.

Jacquet-Lagrèze, E., Siskos, Y., 2001. Preference disaggregation: 20 years of MCDA experience. European Journal of Operational Research, 130(2), 233-245.

Keeney, R.L., Raiffa, H., 1976. Decisions with Multiple Objectives: Preferences and Value Tradeoffs. Willey, New York.

Kleindorfer, P.R., Singhal, K., Van Wassenhove, L.N., 2005. Sustainable Operations Management. Production and Operations Management, 14(4), 482-492.

Lieb, K.J., Lieb, R.C., 2010. Environmental sustainability in the third-party logistics (3PL) industry. International Journal of Physical Distribution \& Logistics Management, 40(7), 524-533.

Linton, J.D., Klassen, R., Jayaraman, V., 2007. Sustainable supply chains: An introduction. Journal of Operations Management, 25(6), 1075-1082.

Miettinen, K., 1999. Nonlinear Multiobjective Optimization. Kluwer Academic Publishers, Boston.

Miettinen, K., Ruiz, F., Wierzbicki, P., 2008. Introduction to Multiobjective Optimization, Interactive Approaches. In: Branke, J. et al., (Eds.): Multiobjective Optimization, Springer, Heidelberg. 
Neumayer, E., 2003. Weak Versus Strong Sustainability: Exploring the Limits of Two Opposing Paradigms. Edward Elgar, Cheltenham, UK.

Porter, M.E., van der Linde, C., 1995. Green and competitive: ending the stalemate. Harvard Business Review, 73(5), 120-134.

Roundy, R., 1985. 98\%-Effective Integer-Ratio Lot-Sizing for One-Warehouse Multi-Retailer Systems. Management Science, 31(11), 1416-1430.²

Roundy, R., 1986. A 98\%-Effective Lot-Sizing Rule for a Multi-Product, Multi-Stage Production / Inventory System. Mathematics of Operations Research, 11(4), 699-727.

Sbihi, A., Eglese, R., 2007. Combinatorial optimization and Green Logistics. 4OR: A Quarterly Journal of Operations Research, 5(2), 99-116.

Schwarz, L.B., 1973. A Simple Continuous Review Deterministic One-Warehouse N-Retailer Inventory Problem. Management Science, 19(5), 555-566.

Seuring, S., Müller, M., 2008. From a literature review to a conceptual framework for sustainable supply chain management. Journal of Cleaner Production, 16(15), 1699-1710.

Siskos, Y., Despotis, D.K., 1989. A DSS oriented method for multiobjective linear programming problems. Decision Support Systems, 5(1), 47-55.

Siskos, Y., Grigoroudis, E., Matsatsinis, N., 2005. UTA methods. In: Figueira, J., Greco, S., Ehrgott, M. (Eds.), Multiple Criteria Decision Analysis: State of the Art Surveys. Springer Verlag, Berlin.

Siskos, Y., Yannacopoulos, D., 1985. UTASTAR: an ordinal regression method for building additive value functions. Investigaç ao Operacional, 5, 39-53.

Stewart, T., 1987. Pruning of decision alternatives in multiple criteria decision making, based on the UTA method for estimating utilities. European Journal of Operational Research, 28(1), 7988 .

Venkat K., 2007. Analyzing and optimizing the environmental performance of supply chains. Proceedings of the ACCEE Summer Study on Energy Efficiency in Industry, White Plains, New York, U.S.

Wakeland, W., Sears, L., Venkat, K., 2009. Measuring the Effects of Carbon Footprint Training on Consumers. Sustainability: The Journal of Record, 2(1), 45-52.

White, L., Lee, G.J., 2009. Operational research and sustainable development: Tackling the social dimension. European Journal of Operational Research, 193(3), 683-692.

Wilson, R.H., 1934. A scientific Routine for Stock Control, Harvard Business Review 13, 116-128.

World Commission on Environment and Development, 1987. Our Common Future. Oxford University Press, Oxford. 